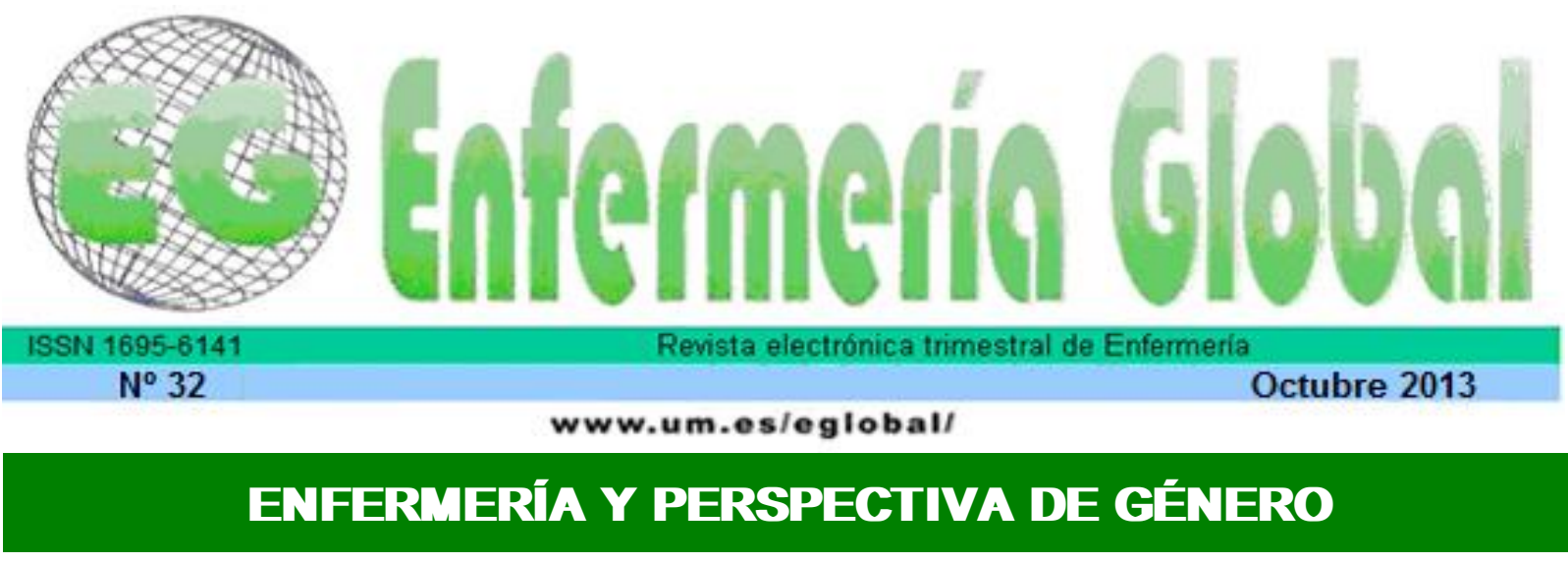

\title{
Política de atención a la Salud del hombre en Brasil y los retos de su implantación: una revisión integrativa
}

Política de Atenção à Saúde do Homem no Brasil e os desafios da sua implantação: uma revisão integrativa

The Politics of Health Care of the Man in Brazil and the challenges of its implementation: an integrative review

\section{${ }^{*}$ Da Silva, Patrick Leonardo Nogueira ${ }^{* *}$ Maciel, Mauro Moreira ${ }^{* * *}$ Carfesan, Carolina Saiberth ${ }^{* * *}$ Santos, Silas ${ }^{* * * *}$ De Souza, Jacqueline Ribeiro}

*Enfermero. Especialista en Salud de la Familia. Pos-Graduando en Didáctica y Metodología de la Enseñanza Superior por la Universidad Estadual de Montes Claros (Unimontes). E-mail: patrick_mocesp70@hotmail.com **Enfermero por la Fundación Presidente Antônio Carlos (Fupac), Uberlândia. ${ }^{* * *}$ Enfermera. Especialista en Enfermería Gerencial, en Docencia de Enseñanza Superior y en Nutrición Clínica. Coordienadora del curso de Graduación en Enfermería de la Fupac de Uberlândia. ****Estudiante del Curso de Graduación en Enfermería de la Fundación Presidente Antônio Carlos (Fupac). Uberlândia. Minas Gerais, ${ }^{* * * * * G r a d u a c ̧ a ̃ o ~ e m ~ L e t r a s ~ E s p a n h o l . ~ M e s t r e ~ e m ~ L e t r a s ~ p e l a ~}$ Universidade Estadual de Montes Claros (Unimontes). Montes Claros, Minas Gerais, Brasil.

Palabras clave: salud del hombre; género y salud; atención primaria de salud. Palavras chave: saúde do homem; gênero e saúde; atenção primária à saúde. Keywords: men' s health; gender and health; primary health care.

\section{RESUMEN}

Este estudio tiene como objetivo identificar los retos para la implementación de la Política Nacional de Atención Integral a la salud humana. Se trata de una revisión integradora que consistió en buscar las bases de datos LILACS, SciELO y BDENF en el período comprendido entre 2000 y 2012. De los resultados encontrados, inicialmente 3.738 artículos presentaban los descriptores Salud del hombre, Género y Salud y Atención Primaria distribuidos en las bases de datos mencionadas. Después de observar la intersección de los descriptores citados, los artículos que presentan la información en contexto que responda a la pregunta de investigación de este estudio se seleccionaron quince (15) artículos de formar parte de esta revisión integradora. Por lo tanto, examinar lo que los hombres buscan en un centro de salud, y a partir de este análisis plantear acciones con el fin de satisfacer las demandas de salud de la población masculina, son medidas que se pueden tomar a través de la reestructuración de las Unidades Básicas de Salud y del trabajo de los profesionales que atienden a los varones. 


\section{RESUMO}

Este estudo objetiva identificar quais os desafios para a implantação da Política Nacional de Atenção Integral à saúde do homem. Trata-se de uma revisão integrativa constituída de busca nas bases de dados LILACS, SCIELO e BDENF no período compreendido entre 2000 e 2012. Aos resultados, inicialmente foram encontrados 3.738 artigos que apresentavam os descritores Saúde do homem, Gênero e Saúde e Atenção Primária distribuídos nas bases de dados citadas. Após observação do cruzamento dos descritores citados, os artigos que apresentam no seu contexto informações que respondem a questão norteadora do presente trabalho foram selecionados quinze (15) artigos para fazer parte da presente revisão integrativa. Portanto, examinar o que o gênero masculino procura em uma unidade de saúde, e a partir dessa análise planejar ações com vistas a atender as demandas de saúde dessa população masculina, são medidas que podem ser tomadas através da reestruturação nas Unidades Básicas de Saúde, bem como na atuação dos profissionais que atendem o gênero masculino.

\section{ABSTRACT}

This study aims to identify the challenges for the implementation of the National Policy for Integral Attention to human health. It is an integrative review consisted of searching the databases LILACS, SciELO and BDENF the period between 2000 and 2012. The results initially found 3,738 articles that presented the descriptors Men's Health, Gender and Health and Primary distributed in the databases mentioned. After observing the intersection of descriptors cited articles that present information in context that answer research question of this study were selected fifteen (15) items to be part of this integrative review. Therefore, examine what males look for in a healthcare facility, and from this analysis plan actions in order to meet the health demands that the male population, are measures that can be taken through restructuring in Basic Health Units and the work of professionals who serve the males.

\section{INTRODUCCIÓN}

Las diferencias en salud entre hombres y mujeres han sido un elemento de gran interés científico representado por estudios que analizan diferenciales de morbidad y utilización de los servicios de salud, que demuestran que en Brasil las mujeres viven más que los hombres y frecuentan más los servicios de salud, lo que refleja la intensa medicalización de los ciclos reproductivos femeninos ${ }^{(1)}$.

A partir de la década de 1990, el sexo masculino pasó a ser abordado separadamente como segmento poblacional en las investigaciónes de los patrones de morbimortalidad que consideraban la diferenciación sexual en los indicadores epidemiológicos ${ }^{(2)}$.

El área de la salud ha puesto atención a la influencia de la construcción social de las masculinidades en la producción de comportamientos de riesgo a la salud y en dificultades relacionadas a la práctica del cuidado $^{(3-4,1)}$.

Agregadas a eso, en las políticas públicas de salud y en la estructura organizacional de los servicios, se volvieron visibles las desigualdades que comprometen la relación de los hombres con los servicios y el cuidado en salud ${ }^{(5-7)}$.

Una gran parte de las investigaciones indica que el género masculino, en general, está más expuesto a situaciones insalubres de trabajo ${ }^{(8)}$, al creciente consumo de alcohol y otras drogas psicoactivas ${ }^{(9)}$, además de buscar el confronto con las situaciones de riesgo, como característica estructurante en la construcción de la identidad masculina, aliada a un sentimiento de invulnerabilidad, lo que implica tasas elevadas de muerte con causas violentas ${ }^{(8)}$. 
Los hombres presentan una situación de salud desfavorable en comparación a las mujeres, principalmente cuando se relaciona a las causas violentas, hecho claramente expresado por los datos de mortalidad de Brasil, en el período de 1991 a $2005^{(10)}$.

Datos del Ministerio de Salud (MS) revelan que los hombres sólo acuden al Sistema Único de Salud (SUS) mediante atención especializada y eso resulta en un aumento de la morbidad por el retraso en la atención y mayor costo al SUS ${ }^{(11)}$.

Los servicios de salud son incapaces en atender la demanda presentada por los hombres, en virtud de su organización que no estimula el acceso de la población masculina a los servicios de salud y también de las propias campañas de salud pública que a menudo no se centran para este segmento ${ }^{(12)}$.

La falta de atención primaria al público masculino impone a los hombres sólo la perspectiva asistencial especializada. En ese sentido, el Estado no pone atención ni relaciona los hombres como blanco de intervenciones en la lógica organizacional de los servicios, cuando se trata de la Atención Primaria a la Salud, y este hecho ubica el hombre sin recursos en el área de las políticas públicas de salud, aspecto que algunos autores consideran como una forma de invisibilidad del grupo masculino ${ }^{(5)}$.

Sin embargo, la eficacia de las acciones del sector público puede estar relacionada con la la cantidad de acciones que consiguen crear vínculos entre los testimonios y las necesidades de salud de los sujetos que pretenden atender ${ }^{(13)}$.

La enfermedad es considerada por los hombres como una señal de fragilidad y no como perteneciente a su propia condición biológica y de ese modo el ambiente de las unidades básicas de salud (USB) es considerado como un ambiente femenino, o sea, un espacio lejano que no es parte de su cotidiano ${ }^{(6)}$.

Un estudio realizado en Rio de Janeiro ha demostrado que las mujeres utilizan con mayor frecuencia los servicios de salud que los hombres, señalando las diferencias de género relacionadas con la obtención de los servicios, en que las mujeres los buscan más para hacer pruebas de rutina y exámenes preventivos, mientras los hombres acuden a causa de enfermedad. ${ }^{(14)}$.

Esa pequeña utilización de los servicios de salud por los hombres se da por el hecho de que ellos presentan una mayor dificultad en acudir a la asistencia de salud en virtud de su auto percepción de necesidades de cuidados y por la asociación de que esta búsqueda es una tarea femenina ${ }^{(15)}$.

Una gran parte de la falta de adherencia a las medidas de atención integral, por parte del hombre, se deriva, muchas veces, de las variaciones culturales y estereotipos de género, enraizados hace siglos en la cultura patriarcal, construidas por prácticas basadas en creencias y valores de masculinidad ${ }^{(11)}$.

Varios estudios comparativos, entre hombres y mujeres, han comprobado las dificultades masculinas en expresar y revelar sus necesidades de salud con consecuente disminución de la obtención, por parte de los hombres, de atención básica. Ese hecho asociado al comportamiento social de los hombres, en que poder, fuerza y éxito son considerados atributos característicos masculinos, resultan en 
situaciones que predisponen a las enfermedades graves y crónicas, haciendo que los hombres mueran más temprano que las mujeres ${ }^{(16-17)}$.

Además de eso, en Brasil se percibe que los servicios y las estrategias de comunicación de la salud pública privilegian las acciones de salud para los niños, los adolescentes, las mujeres y los ancianos. Esa constatación ha despertado, en los últimos años, el interés por parte del MS, en discutir y promover la relación de los hombres con los servicios de atención primaria a la salud, los cuales presentan dificultades para buscar prácticas preventivas y promoción de la salud de los hombres ${ }^{(11)}$.

Una cuestión pleiteada por los varones con respecto a poca atención por los servicios de salud está relacionada a la dificultad de acceso a los servicios asistenciales, en virtud del tiempo perdido en las colas para marcar una consulta, que muchas veces resulta en pérdida de un día entero de trabajo, sin mencionar el hecho de que a veces sus cuestiones no son resueltas en una única consulta médica ${ }^{(18)}$.

Otro factor también relatado por los hombres es acerca de los horarios de cuidado de los servicios de salud que coinciden con el horario de trabajo, aunque una gran parcela de la población femenina, de todas las categorías socioeconómicas, actualmente esté inserta en el mercado laboral, y ni por eso deja de acudir a los servicios de salud $^{(12)}$.

Se observa que la población masculina que acude al sistema de salud, lo hace sólo mediante atención especializada, cuando muchas veces ya no hay más solución, mostrándose necesario el uso de mecanismos de fortalecimiento y calificación de la atención primaria para que la atención a la salud no se limite a sólo una tentativa de recuperación de la salud, sino que garantice, sobretodo, la promoción de la salud y la prevención de mayores problemas que pueden ser evitados ${ }^{(11)}$.

En marzo de 2007 con ocasión de la conferencia de toma de posesión del Ministro de la Salud del segundo mandato presidencial de Luiz Inácio Lula da Silva, el médico de sanidad José Gomes Temporão, apuntó de entre las metas que deben ser cumplidas durante la gestión del gobierno, la implementación de una "política nacional que involucre la salud del hombre"(19).

En el año siguiente, en marzo de 2008, fue creado en el ámbito del Departamento de Acciones Programáticas Estratégicas de la Secretaría de Atención a la Salud, una nueva área, el Área Técnica de Salud del Hombre, coordinada por Ricardo Cavalcanti, médico ginecólogo y uno de los fundadores de la moderna sexología brasileña ${ }^{(20)}$.

La Política Nacional de Atención Integral a la Salud del Hombre (PNAISH) está unida a la Política Nacional de Atención Básica, que es el acceso al SUS, y con las estrategias de humanización en salud, en concordancia con los principios del SUS ${ }^{(7)}$, fortaleciendo acciones y servicios en redes y cuidados de la salud, privilegiando la Estrategia de Salud de la Familia, evitando con eso la sectorización de servicios o la segmentación de estructuras ${ }^{(11)}$.

La Política Nacional de Atención Integral a la Salud del Hombre convoca a los actores y instituciones de los servicios de salud en Brasil para discutir esa temática. De la misma manera como otras políticas públicas dirigidas a grupos sociales discriminados son marcos políticos importantes, las políticas de salud deben ser eficaces para una 
mejora del SUS, en especial, a partir de sus principios básicos y no como una carga más en un sistema sobrecargado ${ }^{(9)}$.

Al reconocer el aumento de las enfermedades de los hombres, que constituyen verdaderos problemas de salud pública, el Ministerio de la Salud ha formulado una Política Nacional que objetiva guiar las acciones de atención integral a la salud del hombre, mirando estimular el auto cuidado y, sobretodo, el reconocimiento de que la salud es un derecho social básico y de ciudadanía de todos los hombres brasileños $^{(11)}$.

Uno de los principales objetivos de esta Política es promover acciones de salud que posibiliten el aumento de la expectativa de vida y la reducción de los índices de morbimortalidad a través de educación y prevención de los varones.

Por lo tanto, comprender los obstáculos socioculturales e institucionales es importante para la proposición estratégica de medidas que vengan a promover el acceso de los hombres a los servicios de atención primaria, a fin de resguardar la prevención y la promoción como ejes necesarios y fundamentales de intervención, lo que transforma esa política de gran importancia en el contexto de la salud masculina.

Ante de la importancia del tema, es relevante discutir e investigar los retos y obstáculos encontrados por el Ministerio de Salud para la implementación de la Política Nacional de Atención Integral a la Salud del Hombre y, por consiguiente se justifica el presente estudio.

Así que este estudio presenta la siguiente cuestión como guía: "Desde el lanzamiento de la Política Nacional de Atención Integral a la Salud del Hombre por el gobierno brasileño, en 2008, ¿cuáles son los retos que esa política han enfrentado para su implementación?".

\section{METODOLOGÍA}

Para la realización de este estudio, se llevó a cabo una revisión integradora, método este que acepta que el autor evalúe de forma crítica los resúmenes de los énfasis disponibles del tema investigado ${ }^{(21)}$, lo que presenta como resultado la adquisición actual del conocimiento del tema investigado, la toma de intervenciones concretas en la asistencia a la salud para la disminución de los costos dirigidos a la salud, además del acercamiento a algunos aspectos que contribuyen al desarrollo de futuras investigaciones.

En la revisión integradora ocurre la combinación de datos de la literatura teórica y empírica, además de agrupar una enorme cantidad de finalidades, definiciones de conceptos, revisión de teorías y evidencias, y análisis de problemas metodológicos de un tópico particular ${ }^{(22)}$.

Para que el método sea utilizado es necesario seguir algunas fases, las cuales fueron desarrolladas para la elaboración de este estudio. Un problema relacionado con los servicios de salud dirigidos a los varones es que una gran parte de ellos son considerados poco aptos para absorber la demanda presentada por los hombres, pues su organización no estimula el acceso y las propias campañas de salud pública no se centran en este segmento, y es en este escenario que surge la proposición de la Política Nacional de Atención Integral a la Salud del Hombre que intenta calificar la 
atención a la salud de la población masculina en la perspectiva de establecer líneas de cuidado que resguarden la integridad de la atención a la salud.

Es evidente la necesidad de nuevas reflexiones acerca de la salud de los hombres y así nuevas discusiones surgieron y pasaron a incorporar algunas relaciones como el género, determinantes del proceso de salud/enfermedad, y a rescatar a los hombres como sujetos del derecho a la salud a través de la implementación de la Política Nacional de Atención Integral al Hombre ${ }^{(23)}$.

La base de pesquisa es el banco de datos de la Biblioteca Virtual em Saúde (BVS), utilizando como fuentes la Literatura Latino Americana y del Caribe en Ciencias de la Salud (LILACS), el Banco de Base de Datos de Enfermería (BDENF) y Scientific Electronic Libray Online (SCIELO).

La muestra del estudio estuvo constituida por todas las publicaciones indexadas en el banco de datos de las citadas fuentes, que abordan la cuestión que guía este estudio. Fueron incluidos textos y resúmenes en los idiomas inglés, español y portugués, y excluidos sólo los estudios publicados en duplicidad en más de una base de datos. Inicialmente en la búsqueda en la BVS la consulta atendió al criterio de la presencia de los Descriptores en Ciencias de la Salud (DeCS): Salud del Hombre, Género y Salud, Atención Primaria a la Salud.

En la evaluación para la selección de los artículos se observaron algunas características de los estudios y para realizar la colecta de los datos fue elaborado un guión conteniendo identificación del artículo (número, título, periódico, base de datos, autores, año de publicación, metodología de la pesquisa, criterios de inclusión y exclusión, actividad laboral de los autores e informaciones sobre el lanzamiento de implementación de la Política Nacional de Atención Integral a la Salud del Hombre). La síntesis de los datos extraídos de los artículos será presentada a continuación de forma descriptiva en tablas, reuniendo el conocimiento producido sobre el asunto investigado en la presente revisión integradora.

Las dos categorías temáticas relacionadas a los desafíos y obstáculos encontrados por el Ministerio de la Salud para la implementación de la Política Nacional de Atención Integral a la Salud del Hombre, fueron divididas en la presente revisión en: 1) Factores intrínsecos al género masculino: Dificultades masculinas en expresar y revelar sus necesidades de salud con consecuente disminución de la búsqueda por los mismos de las UBS, en virtud de las variables culturales y estereotipos de género, enraizados hace siglos en una cultura patriarcal, construidas de prácticas basadas en creencias y valores de masculinidad; 2) Factores extrínsecos: Dificultad de acceso a los servicios asistenciales, en virtud del tiempo perdido en las colas para marcar la consulta médica lo que muchas veces resulta en la pérdida de un día entero de trabajo, sin mencionar el hecho de que a veces sus cuestiones no son resueltas en una única consulta.

Este procedimiento favorecerá el desarrollo de teorías y recomendaciones de investigaciones futuras para la proposición estratégica de medidas que vengan a promover el acceso de los hombres a los servicios de atención primaria, a fin de resguardar la prevención y la promoción como ejes necesarios y fundamentales de intervención, lo que transforma esa política de gran importancia en el contexto de la salud masculina. El análisis, discusión e interpretación de los resultados incluyen 
informaciones suficientes para que el lector pueda examinar críticamente las evidencias levantadas y sus implicaciones para la práctica de la pesquisa.

La presente revisión dispone de informaciones suficientes que permitirán al lector la posibilidad de realizar análisis críticos de los procedimientos empleados en la elaboración de la misma, de los aspectos relativos al tema abordado y de los detalles de los estudios incluidos. La propuesta de la presente revisión integradora fue reunir y sintetizar las evidencias disponibles en la literatura. Con eso, ha procurado articular el resultado del análisis de los bancos de datos en el intento de responder a la cuestión que guía este estudio, lo que será presentado y discutido sucesivamente a continuación.

\section{RESULTADOS}

La búsqueda de los artículos fue realizada inicialmente en el banco de datos de la BVS. Investigando la presencia de los DeCS: Salud del hombre, Género y Salud y Atención Primaria. Fue obedecida la presencia del descriptor exacto, en el idioma Portugués y consulta por índice permutado. Fueron encontrados 64.555 artículos que fueron cruzados entre sí, conforme Tabla 1.

Tabla 1 - Intersección de los Descriptores: Salud del Hombre, Género y Salud y Atención Primaria a la Salud para la búsqueda total BVS.

\begin{tabular}{|c|c|c|c|c|}
\hline Descriptores & $\begin{array}{l}\text { Salud del } \\
\text { Hombre }\end{array}$ & $\begin{array}{l}\text { Género } \\
\text { Salud }\end{array}$ & $\mathrm{y}$ & $\begin{array}{l}\text { Atención Primaria a } \\
\text { la Salud }\end{array}$ \\
\hline Salud del Hombre & 1.090 & 11 & & 38 \\
\hline Género y Salud & 11 & 245 & & 08 \\
\hline $\begin{array}{l}\text { Atención Primaria a la } \\
\text { Salud }\end{array}$ & 38 & 08 & & 63.220 \\
\hline
\end{tabular}

Fuente: Artículos de las bases de datos online de la Biblioteca Virtual de Saúde (BVS).

Los artículos presentaban las siguientes las palabras clave: Salud del Hombre/Política Nacional de la Salud del Hombre/Salud y Género Masculino, separadamente, distribuidos en el BVS, teniendo como fuentes a LILACS, BDENF y SCIELO, conforme Tabla 2.

Tabla 2 - Distribución de las referencias obtenidas en el BVS, de acuerdo con las palabras clave Salud del Hombre/Política Nacional de la Salud del Hombre/Salud y Género Masculino, en los resúmenes de los artículos.

\begin{tabular}{llcc}
\hline Fuentes & Descriptores & $\begin{array}{c}\text { Año de } \\
\text { publicación }\end{array}$ & $\begin{array}{l}\text { No de Referencias } \\
\text { obtenidas }\end{array}$ \\
\hline LILACS & $\begin{array}{l}\text { Salud del Hombre/Género } \\
\text { y Salud/Atención Primaria } \\
\text { a la Salud } \\
\text { Salud del Hombre/Género } \\
\text { y Salud/Atención Primaria }\end{array}$ & 2000 a 2012 & 2.782 \\
BDENF & $\begin{array}{l}\text { a la Salud } \\
\text { Salud del Hombre/Género } \\
\text { y Salud/Atención Primaria } \\
\text { a la Salud }\end{array}$ & 2012 & 29.507 \\
\hline TOTAL & & 312 \\
\hline
\end{tabular}

Fuente: Artículos de las bases de datos online de la Biblioteca Virtual de Saúde (BVS). 
Es interesante señalar que al cruzar los tres descriptores a la vez (Salud del Hombre; Género y Salud y Atención Primaria a la Salud), la búsqueda tuvo como resultado cuatro (04) artículos.

Sin embargo, con vistas a una muestra representativa, una nueva selección fue realizada, pero ahora optando por la elección de textos completos y publicados entre 2000 y 2012, en las fuentes LILACS, SCIELO y BDENF. Fue observado en la intersección de los descriptores salud del hombre y género y salud; salud del hombre y atención primaria a la salud; atención primaria a la salud y género y salud. Los artículos que presentaran en su contexto informaciones que pudieran contestar la cuestión que guía este trabajo serían seleccionados. Luego, quince (15) artículos fueron seleccionados para componer esta revisión integradora.

La próxima etapa de la investigación fue reservada a la identificación de algunos aspectos de los artículos seleccionados como: el título, el periódico donde fueron publicados, los autores y el área profesional de cada uno, como se muestra en la Tabla 3.

Tabla 3 - Distribución de los artículos seleccionados de acuerdo con la base de datos, título de los artículos, periódico, autores/Año y respectivas áreas laborales.

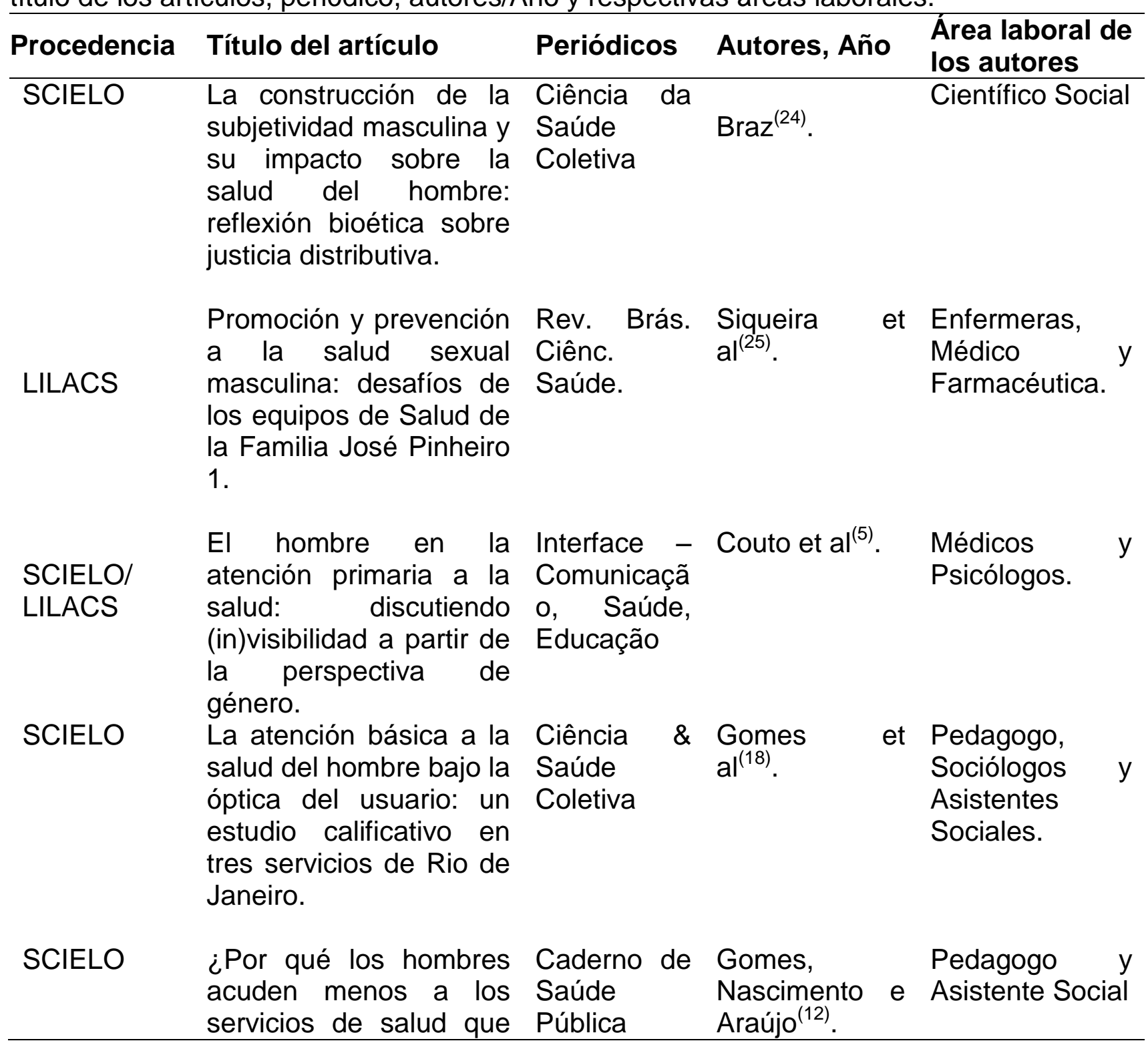




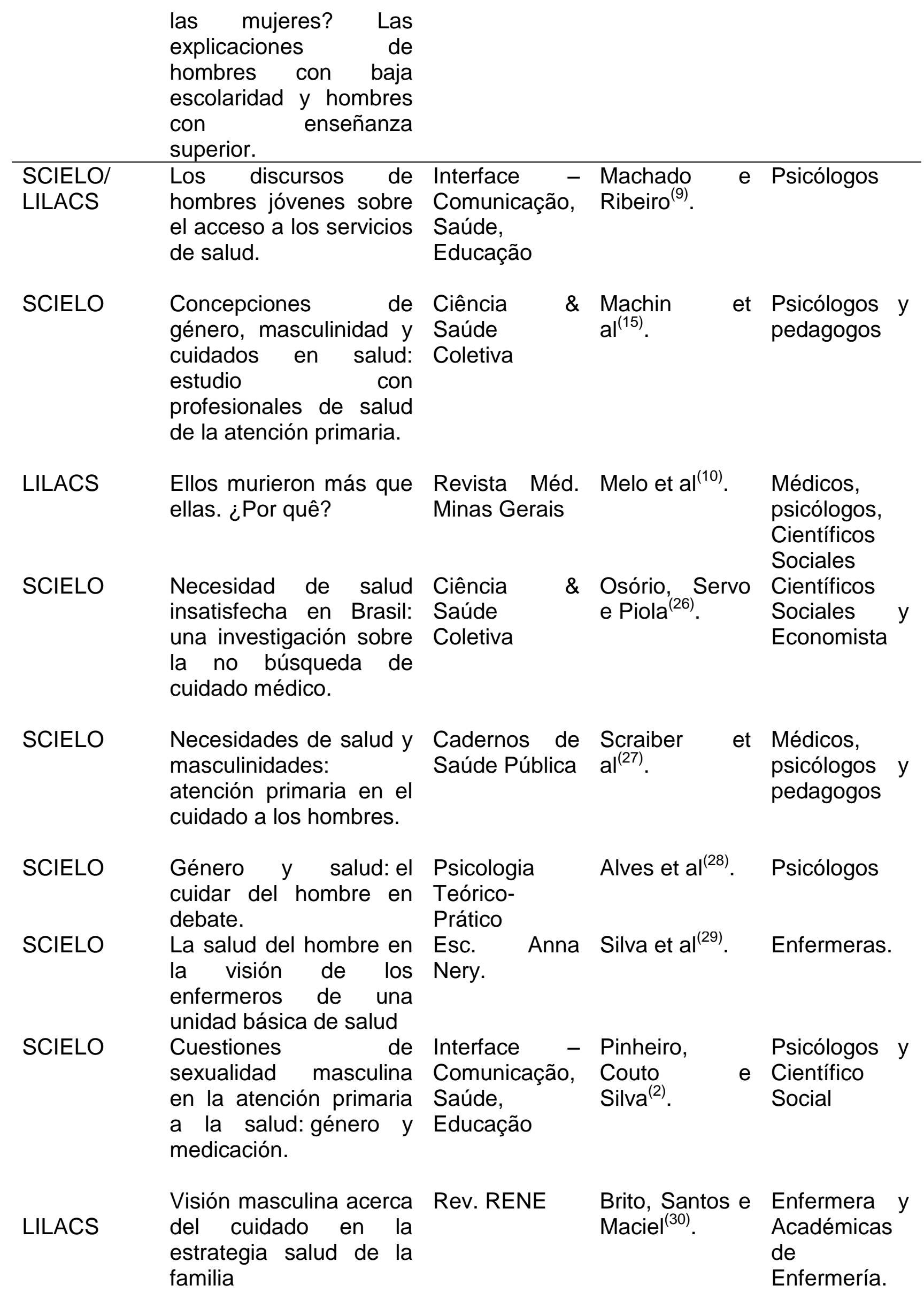




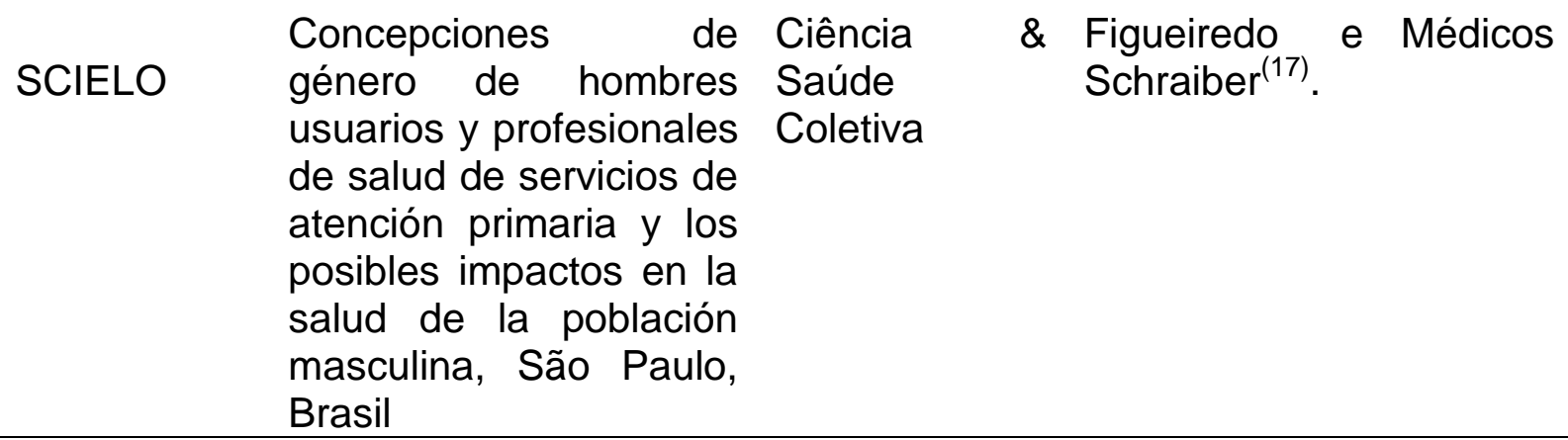

Fuente: $\quad$ Artículos de las bases de datos online de la Biblioteca Virtual de Saúde (BVS).

La etapa siguiente fue dirigida al análisis de los parámetros utilizados por los autores como: metodología, objetivo, tipo de selección y caracterización y los criterios de inclusión y exclusión. Los datos están presentados en la Tabla 4.

Tabla 4 - Caracterización de los estudios en cuanto a la metodología, objetivo, tipo de selección/caracterización y criterios de inclusión de los artículos.

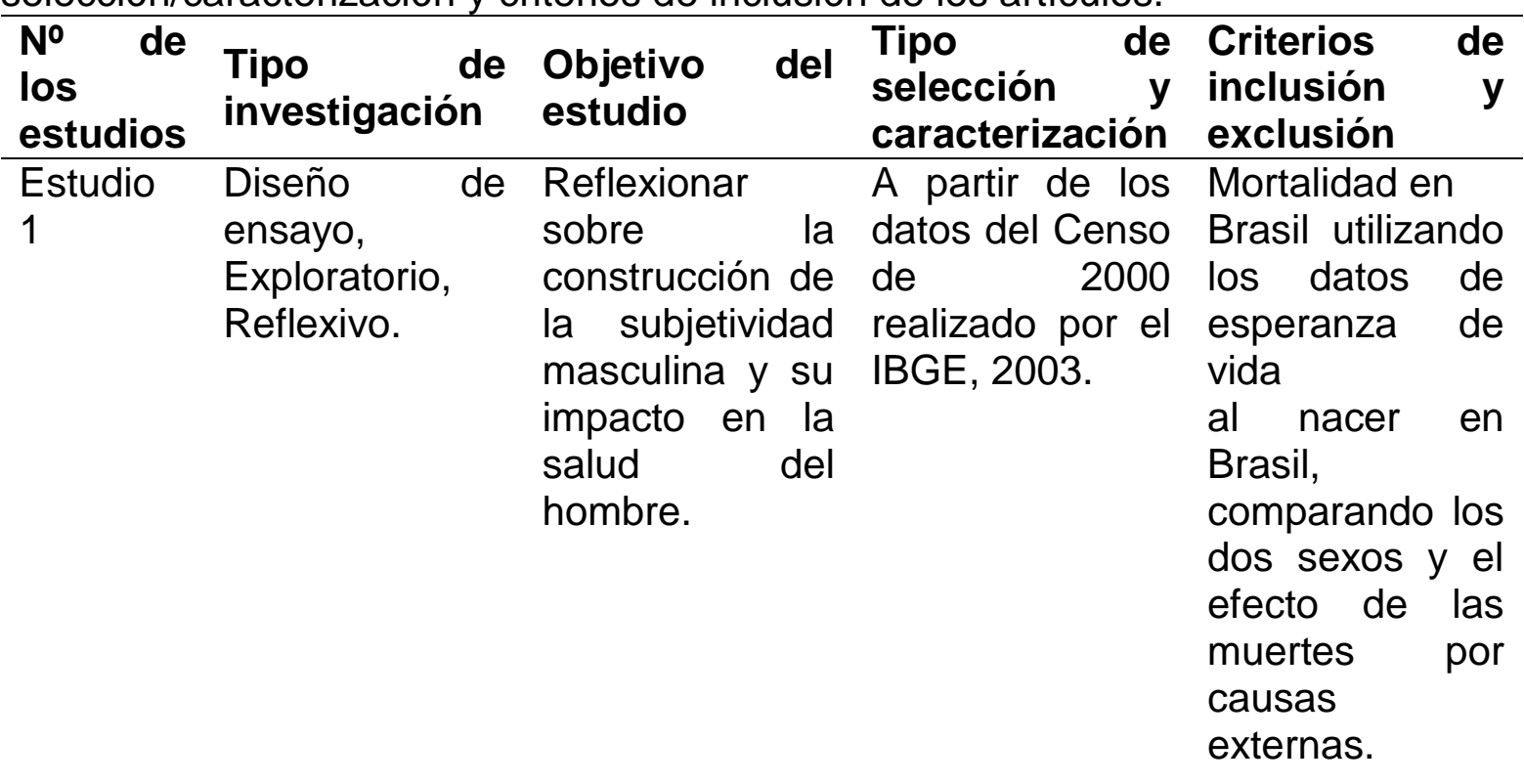

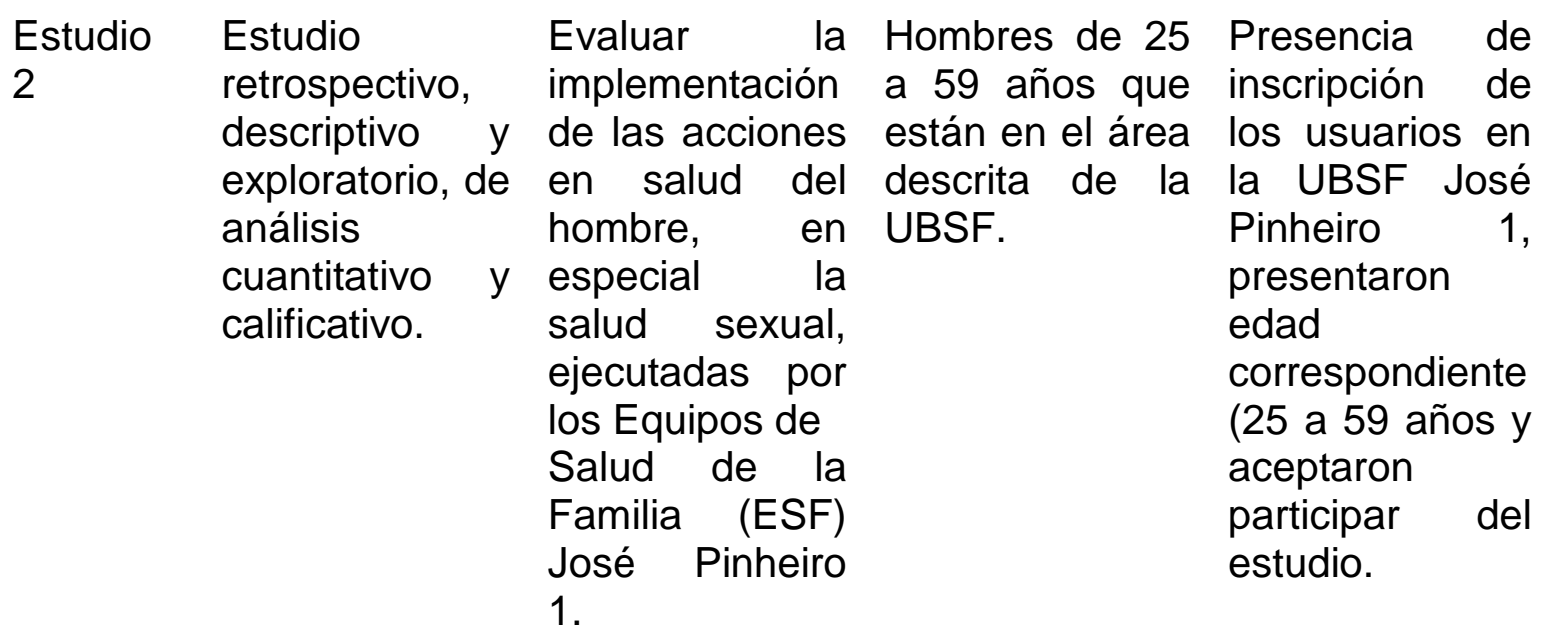




\begin{tabular}{|c|c|c|c|c|}
\hline $\begin{array}{l}\text { Estudio } \\
3\end{array}$ & $\begin{array}{l}\text { Investigación } \\
\text { multicéntrica } \\
\text { de carácter } \\
\text { etnográfico }\end{array}$ & $\begin{array}{l}\text { Comprender la } \\
\text { (in) visibilidad } \\
\text { de los hombres } \\
\text { en el cotidiano } \\
\text { de la asistencia } \\
\text { a partir de la } \\
\text { perspectiva de } \\
\text { género, que } \\
\text { discute los } \\
\text { mecanismos de } \\
\text { promotores de } \\
\text { desigualdades } \\
\text { presentes en el } \\
\text { trabajo en } \\
\text { salud. }\end{array}$ & $\begin{array}{l}\text { Los servicios de } \\
\text { Atención } \\
\text { Primaria a la } \\
\text { Salud (APS), lo } \\
\text { que totaliza } \\
\text { ocho campos, } \\
\text { modificados, } \\
\text { respectivamente } \\
\text { al estado a que } \\
\text { pertenecen, } \\
\text { como: } \\
\text { Pernambuco } 1 \text { y } \\
2 \text { (PE1 y PE2), } \\
\text { Rio de Janeiro } 1 \\
\text { y } 2 \text { (RJ1 y RJ2), } \\
\text { Rio Grande do } \\
\text { Norte 1 y } 2 \\
\text { (RN1 e RN2) y } \\
\text { São Paulo } 1 \text { y } 2 \\
\text { (SP1 y SP2). }\end{array}$ & $\begin{array}{l}\text { Considerados } \\
\text { los requisitos: } \\
\text { tiempo de } \\
\text { funcionamiento } \\
\text { de al menos } \\
\text { diez años, } \\
\text { siendo que el } \\
\text { equipo de salud } \\
\text { en actividad } \\
\text { funcione hace, } \\
\text { al menos, dos } \\
\text { años; presenten } \\
\text { volumen de } \\
\text { demanda igual } \\
\text { o superior a mil } \\
\text { cuidados/mes; } \\
\text { posea equipo } \\
\text { multiprofesional. }\end{array}$ \\
\hline
\end{tabular}

Tabela 4 - Caracterización de los estudios cuanto a la metodología, objetivo, tipo de selección/caracterización y criterios de inclusión de los artículos. (Cont.)

\begin{tabular}{|c|c|c|c|c|}
\hline $\begin{array}{l}\text { № de } \\
\text { los } \\
\text { estudios }\end{array}$ & $\begin{array}{l}\text { Tipo de } \\
\text { investigación }\end{array}$ & $\begin{array}{l}\text { Objetivo del } \\
\text { estudio }\end{array}$ & $\begin{array}{lr}\text { Tipo de } \\
\text { selección y } \\
\text { caracterización }\end{array}$ & $\begin{array}{lr}\text { Criterios } & \text { de } \\
\text { inclusión } & \text { y } \\
\text { exclusión } & \\
\end{array}$ \\
\hline $\begin{array}{l}\text { Estudio } \\
4\end{array}$ & $\begin{array}{l}\text { Investigación } \\
\text { calificativa, } \\
\text { involucrando } \\
\text { encuestas semi } \\
\text { estructuradas, } \\
\text { método de } \\
\text { interpretación de } \\
\text { sentidos. }\end{array}$ & $\begin{array}{l}\text { Analizar los } \\
\text { sentidos } \\
\text { atribuidos por } \\
\text { usuarios } \\
\text { hombres al al } \\
\text { cuidado que les } \\
\text { es prestado en } \\
\text { el ámbito de la } \\
\text { atención básica } \\
\text { a la salud, } \\
\text { buscando } \\
\text { subsidiar la } \\
\text { construcción de } \\
\text { indicadores } \\
\text { calificativos de } \\
\text { satisfacción con } \\
\text { respecto al uso } \\
\text { de esos } \\
\text { servicios por } \\
\text { usuarios masculinos. } \\
\text { muar }\end{array}$ & $\begin{array}{l}201 \text { usuarios de } \\
\text { cuatro estados } \\
\text { brasileños: PE, } \\
\text { RJ, RN y SP. }\end{array}$ & $\begin{array}{l}\text { Hombres en } \\
\text { las siguientes } \\
\text { edades: } 15 \text { a } \\
25 \text { años, } 26 \text { a } \\
45 \text { y } 46 \text { a } 65 .\end{array}$ \\
\hline $\begin{array}{l}\text { Estudio } \\
5\end{array}$ & $\begin{array}{l}\text { Investigación } \\
\text { calificativa, } \\
\text { involucrando } \\
\text { método } \\
\text { investigativo. }\end{array}$ & $\begin{array}{l}\text { Analizar las } \\
\text { explicaciones } \\
\text { presentes en } \\
\text { discursos } \\
\text { masculinos }\end{array}$ & $\begin{array}{l}\text { Personas } \\
\text { conocidas del } \\
\text { investigador } \\
\text { indican otras } \\
\text { para que sean }\end{array}$ & $\begin{array}{l}18 \text { hombres, } \\
\text { divididos en } \\
\text { dos grupos: } \\
\text { hombres con } \\
\text { poca }\end{array}$ \\
\hline
\end{tabular}




\begin{tabular}{|c|c|c|c|c|}
\hline & & $\begin{array}{lr}\text { para la baja } \\
\text { obtención } & \text { por } \\
\text { servicios } & \text { de } \\
\text { salud. } & \end{array}$ & $\begin{array}{l}\text { encuestadas, } \\
\text { que, a su vez, } \\
\text { indican otras } \\
\text { conocidas. }\end{array}$ & $\begin{array}{l}\text { ninguna } \\
\text { escolaridad } \\
\text { (Grupo I) y } \\
\text { hombres con } \\
\text { Enseñanza } \\
\text { Superior } \\
\text { (Grupo II) }\end{array}$ \\
\hline $\begin{array}{l}\text { Estudio } \\
6\end{array}$ & $\begin{array}{l}\text { Investigación } \\
\text { calificativa, } \\
\text { participativa, } \\
\text { exploratoria. }\end{array}$ & $\begin{array}{l}\text { Reflexionar } \\
\text { sobre la } \\
\text { producción } \\
\text { discursiva en la } \\
\text { relación entre } \\
\text { los hombres } \\
\text { jóvenes y los } \\
\text { servicios de } \\
\text { salud de una } \\
\text { comunidad } \\
\text { tradicional } \\
\text { pesquera de } \\
\text { artesanos, } \\
\text { totalmente } \\
\text { cubierta por la } \\
\text { Estrategia de } \\
\text { Salud de la } \\
\text { Familia, en el } \\
\text { municipio de } \\
\text { Maceió/AL. }\end{array}$ & $\begin{array}{l}\text { Informaciones } \\
\text { obtenidas por } \\
\text { medio de } \\
\text { observación } \\
\text { participante, de } \\
\text { los datos de la } \\
\text { Secretaría } \\
\text { Municipal de } \\
\text { Salud y de los } \\
\text { grupos de } \\
\text { discusión } \\
\text { realizados con } \\
\text { los hombres } \\
\text { jóvenes. }\end{array}$ & $\begin{array}{l}\text { Hombres } \\
\text { jóvenes, con } \\
\text { edad entre } \\
\text { veinte y treinta } \\
\text { años, } \\
\text { afincados en } \\
\text { Pontal da } \\
\text { Barra, Maceió } \\
\text { - Alagoas, } \\
\text { Brasil. }\end{array}$ \\
\hline
\end{tabular}

Tabla 4 - Caracterización de los estudios cuanto a la metodología, objetivo, tipo de selección/caracterización y criterios de inclusión de los artículos. (Cont.)

\begin{tabular}{|c|c|c|c|c|}
\hline $\begin{array}{l}\text { № de } \\
\text { los } \\
\text { estudios }\end{array}$ & $\begin{array}{l}\text { Tipo de } \\
\text { investigación }\end{array}$ & $\begin{array}{l}\text { Objetivo del } \\
\text { estudio }\end{array}$ & $\begin{array}{lr}\text { Tipo } & \text { de } \\
\text { selección y } & \text { yaracterización }\end{array}$ & $\begin{array}{lr}\text { Criterios } & \text { de } \\
\text { inclusión } & \text { y } \\
\text { exclusión } & \end{array}$ \\
\hline $\begin{array}{l}\text { Estudio } \\
7\end{array}$ & $\begin{array}{l}\text { Investigación } \\
\text { multicéntrica de } \\
\text { naturaleza } \\
\text { calificativa } \\
\text { teniendo por } \\
\text { referencia a } \\
\text { triangulación de } \\
\text { métodos. }\end{array}$ & $\begin{array}{l}\text { Analizar las } \\
\text { concepciones } \\
\text { de género y } \\
\text { masculinidades } \\
\text { de } \\
\text { profesionales } \\
\text { de salud de la } \\
\text { Atención } \\
\text { Primaria a la } \\
\text { Salud en cuatro } \\
\text { estados del } \\
\text { país (PE, RJ, } \\
\text { RN, SP) a partir } \\
\text { de dos } \\
\text { perspectivas: } \\
\text { los significados } \\
\text { asociados a ser } \\
\text { hombre y la } \\
\text { relación y } \\
\text { masculinidad y }\end{array}$ & $\begin{array}{l}\text { Como criterio de } \\
\text { selección de las } \\
\text { unidades fue } \\
\text { considerado: } \\
\text { tiempo de } \\
\text { funcionamiento } \\
\text { de al menos } 10 \\
\text { años; } \\
\text { presentaron } \\
\text { volumen de } \\
\text { demanda } \\
\text { superior } \\
1.000 \\
\text { cuidados/mes; de } \\
\text { y, poseer } \\
\text { equipo } \\
\text { multiprofesional. }\end{array}$ & $\begin{array}{l}\text { Fueron } \\
\text { analizadas } 69 \\
\text { encuestas en } \\
\text { profundidad de } \\
\text { profesionales } \\
\text { de salud con } \\
\text { formación de } \\
\text { nivel superior } \\
\text { de seis } \\
\text { ciudades } \\
\text { (Natal, Recife, } \\
\text { Olinda, Rio de } \\
\text { Janeiro, São } \\
\text { Paulo y Santos) }\end{array}$ \\
\hline
\end{tabular}




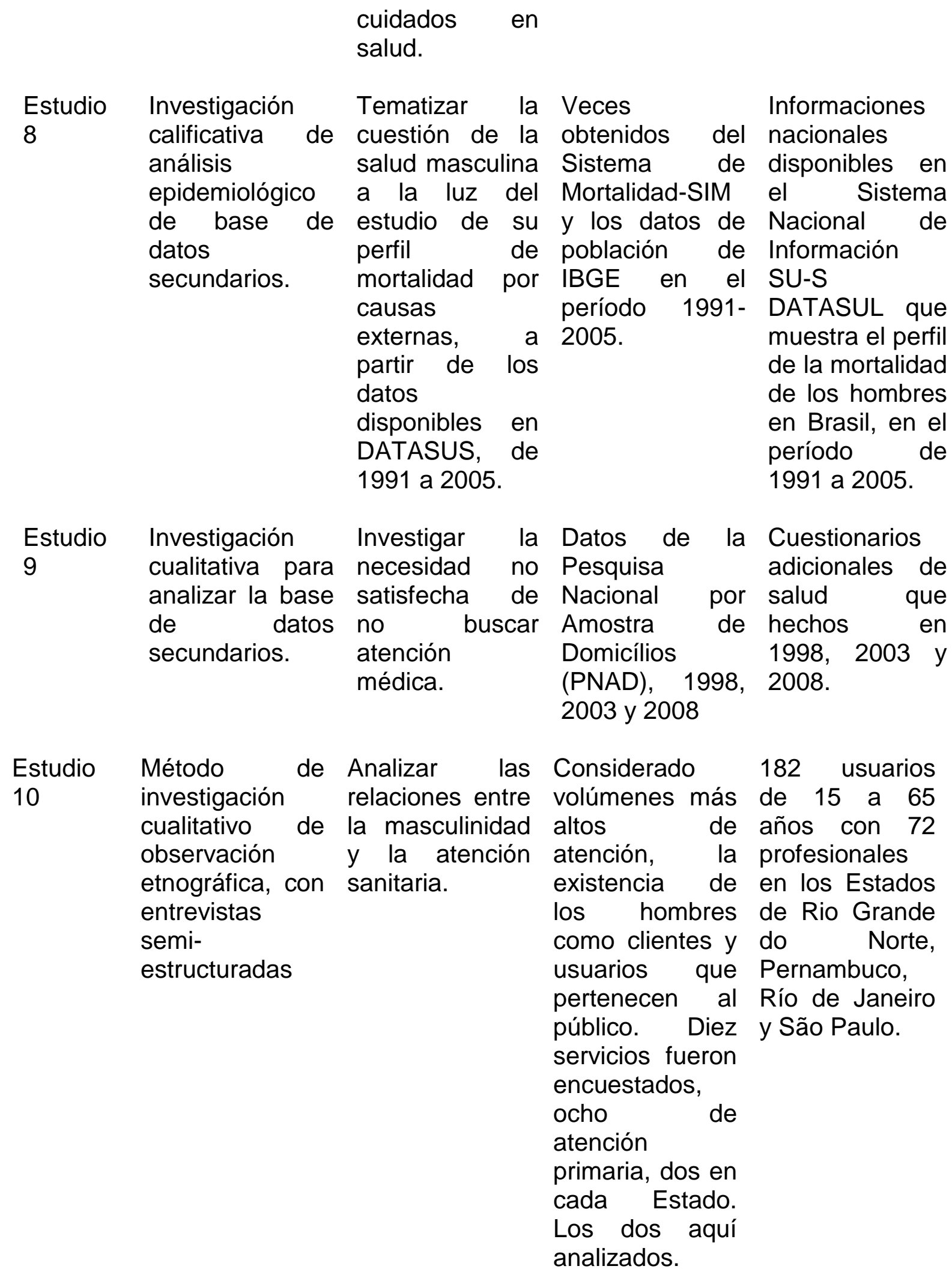


Tabla 4 - Caracterización de los estudios en cuanto a la metodología, objetivo, tipo de selección/caracterización y criterios de inclusión de los artículos. (Cont.)

\begin{tabular}{|c|c|c|c|c|}
\hline $\begin{array}{l}\text { № de } \\
\text { los } \\
\text { estudios }\end{array}$ & $\begin{array}{l}\text { Tipo de } \\
\text { investigación }\end{array}$ & $\begin{array}{l}\text { Objetivo del } \\
\text { estudio }\end{array}$ & $\begin{array}{lr}\text { Tipo } & \text { de } \\
\text { selección y } & \text { y } \\
\text { caracterización }\end{array}$ & $\begin{array}{lr}\text { Criterios } & \text { de } \\
\text { inclusión } & \text { y } \\
\text { exclusión } & \\
\end{array}$ \\
\hline $\begin{array}{l}\text { Estudio } \\
11\end{array}$ & 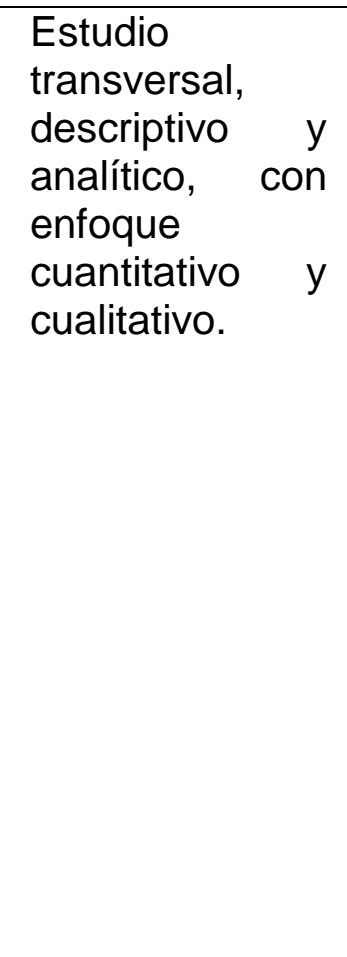 & $\begin{array}{l}\text { Analizar el } \\
\text { cuidado de la } \\
\text { salud auto } \\
\text { relatado por los } \\
\text { hombres, y } \\
\text { comprender } \\
\text { sus } \\
\text { percepciones } \\
\text { sobre las } \\
\text { formas en que } \\
\text { hombres y } \\
\text { mujeres se } \\
\text { ocupan de su } \\
\text { propia salud. }\end{array}$ & $\begin{array}{l}\text { Dos muestras } \\
\text { de hombres } \\
\text { entre } 25 \text { y } 59 \\
\text { años: muestra } \\
\text { de número } 1, \\
\text { que consiste en } \\
\text { hombres que } \\
\text { suelen buscan } \\
\text { ayuda en UBSF } \\
\text { y la muestra de } \\
\text { número } 2, \\
\text { compuesta de } \\
\text { hombres que, } \\
\text { aunque inscritos } \\
\text { en } \\
\text { programas los de } \\
\text { salud de la } \\
\text { familia no } \\
\text { suelen buscar } \\
\text { estos servicios. }\end{array}$ & $\begin{array}{l}\text { La muestra } \\
\text { estuvo } \\
\text { conformada por } \\
\text { hombres de } \\
\text { entre 25 y } 59 \\
\text { años, inscritos } \\
\text { en un Programa } \\
\text { de Salud } \\
\text { Familiar (N = } \\
82)\end{array}$ \\
\hline $\begin{array}{l}\text { Estudio } \\
12\end{array}$ & $\begin{array}{l}\text { Investigación } \\
\text { cualitativa y el } \\
\text { análisis de } \\
\text { contenido. }\end{array}$ & $\begin{array}{l}\text { Comprender y } \\
\text { analizar las } \\
\text { opiniones de } \\
\text { los enfermeros } \\
\text { en relación al } \\
\text { cuidado de la } \\
\text { salud del } \\
\text { hombre. } \\
\text { Investigación } \\
\text { cualitativa que } \\
\text { tuvo como } \\
\text { campo de } \\
\text { estudio un } \\
\text { Centro de } \\
\text { Salud de la } \\
\text { Ciudad. }\end{array}$ & $\begin{array}{l}\text { Siete } \\
\text { enfermeros } \\
\text { (tres hombres y } \\
\text { cuatro mujeres). }\end{array}$ & $\begin{array}{l}\text { Los } \\
\text { profesionales } \\
\text { que desarrollan } \\
\text { sus actividades } \\
\text { laborales junto } \\
\text { a la población } \\
\text { masculina, y, } \\
\text { que tienen } \\
\text { ganas y deseo } \\
\text { de contribuir en } \\
\text { la investigación. }\end{array}$ \\
\hline
\end{tabular}

\begin{tabular}{|c|c|c|c|c|}
\hline $\begin{array}{l}\text { Estudio } \\
13\end{array}$ & $\begin{array}{l}\text { Estudio } \\
\text { multicéntrico } \\
\text { dirigido por la } \\
\text { etnografía. }\end{array}$ & $\begin{array}{l}\text { Discutir el } \\
\text { enfoque de la } \\
\text { sexualidad } \\
\text { masculina en la } \\
\text { Atenção } \\
\text { Primária de } \\
\text { Saúde (APS). }\end{array}$ & $\begin{array}{l}\text { La investigación } \\
\text { de do } \\
\text { Unidades } \\
\text { Básicas de } \\
\text { Saúde } \\
\text { (UBS) en Natal } \\
\text { / RN, ocurrido } \\
\text { entre agosto de } \\
2007 \text { y marzo } \\
\text { de } 2008 .\end{array}$ & $\begin{array}{l}\text { Se consideraron: } \\
\text { el tiempo de } \\
\text { funcionamiento } \\
\text { de al menos diez } \\
\text { años - con el } \\
\text { equipo de salud } \\
\text { activa trabajaba } \\
\text { durante al an an } \\
\text { menos dos años, } \\
\text { el volumen de la }\end{array}$ \\
\hline
\end{tabular}


Entrevistamos a 29 hombres en la UBS 1 y 28 en la UBS2, con un total de 57 entrevistas en Natal / RN demanda igual o superior a mil llamadas / mes, la presencia del equipo multidisciplinario, la sensibilidad $y$ disponibilidad de la gestión de la integración de la investigación.

Tabla 4 - Caracterización de los estudios en cuanto a la metodología, objetivo, tipo de selección/caracterización y criterios de inclusión de los artículos. (Cont.)

\begin{tabular}{|c|c|c|c|c|}
\hline $\begin{array}{l}\text { № de } \\
\text { los } \\
\text { estudios }\end{array}$ & $\begin{array}{l}\text { Tipo de } \\
\text { investigación }\end{array}$ & $\begin{array}{l}\text { Objetivo } \\
\text { estudio }\end{array}$ & $\begin{array}{lr}\text { Tipo de } \\
\text { selección y } \\
\text { caracterización }\end{array}$ & $\begin{array}{lr}\text { Criterios } & \text { de } \\
\text { inclusión } & \text { y } \\
\text { exclusión } & \end{array}$ \\
\hline $\begin{array}{l}\text { Estudio } \\
14\end{array}$ & $\begin{array}{l}\text { Estudio } \\
\text { exploratorio y } \\
\text { descriptivo con } \\
\text { enfoque } \\
\text { cualitativo }\end{array}$ & $\begin{array}{l}\text { Identificar la } \\
\text { opinión de } \\
\text { hombres sobre } \\
\text { la atención } \\
\text { recibida en la } \\
\text { Estrategia Salud } \\
\text { de la Familia. }\end{array}$ & $\begin{array}{l}\text { 11 hombres } \\
\text { inscritos en el } \\
\text { área de la } \\
\text { asistencia de un } \\
\text { equipo de la } \\
\text { EFS. }\end{array}$ & $\begin{array}{l}\text { Poseer las } \\
\text { facultades } \\
\text { mentales } \\
\text { conservadas, } \\
\text { se adscriben } \\
\text { en el área de } \\
\text { influencia del } \\
\text { equipo EFS } \\
\text { seleccionada e } \\
\text { inserta en el } \\
\text { grupo de edad } \\
\text { de } 20-59 \text { años. }\end{array}$ \\
\hline & $\begin{array}{l}\text { Estudio con } \\
\text { enfoque } \\
\text { cualitativo, } \\
\text { utilizando dos } \\
\text { técnicas de } \\
\text { investigación: } \\
\text { observación y } \\
\text { encuestas } \\
\text { semi } \\
\text { estructuradas }\end{array}$ & $\begin{array}{l}\text { Discutir las } \\
\text { representaciones } \\
\text { que los usuarios } \\
\text { y los } \\
\text { trabajadores de } \\
\text { los servicios de } \\
\text { atención primaria } \\
\text { a la salud ponen } \\
\text { de manifiesto } \\
\text { sobre lo que es }\end{array}$ & $\begin{array}{l}\text { Fueron } \\
\text { entrevistados } \\
\text { hombres } \\
\text { usuarios y } \\
\text { profesionales } \\
\text { de salud de dos } \\
\text { servicios de } \\
\text { atención } \\
\text { primaria. }\end{array}$ & $\begin{array}{l}\text { Fueron } \\
\text { seleccionados } \\
\text { para la } \\
\text { investigación } \\
\text { usuarios } \\
\text { masculinos de } \\
\text { dieciocho a } \\
\text { sesenta años y } \\
\text { profesionales } \\
\text { de ambos }\end{array}$ \\
\hline & & se & & $\begin{array}{l}\text { sexos, } \\
\text { formación } \\
\text { universitaria y } \\
\text { nivel } \\
\text { secundario. }\end{array}$ \\
\hline
\end{tabular}

Fuente: $\quad$ Artículos de las bases de datos online de la Biblioteca Virtual de Saúde (BVS).

Los 15 artículos seleccionados en esta revisión también se han evaluado para el tipo de análisis aplicado y los resultados, los datos se presentan en la Tabla 5. 
Tabla 5 - Caracterización de los estudios seleccionados cuanto al tipo de análisis aplicada y resultados.

\begin{tabular}{llll}
\hline $\begin{array}{l}\text { No de los } \\
\text { estudios }\end{array}$ & $\begin{array}{l}\text { Tipo de aplicado } \\
\text { aplisis }\end{array}$ & \multicolumn{1}{c}{ Resultados } \\
\hline Estudio 1 & $\begin{array}{l}\text { Análisis exploratorio } \\
\text { de los datos del Censo } \\
\text { de 2000. }\end{array}$ & $\begin{array}{l}\text { Se hizo evidente, a partir de los datos de } \\
\text { morbimortalidad, que hay una desventaja } \\
\text { significativa en términos de la salud en } \\
\text { comparación con los hombres. Ellos mueren } \\
\text { antes que las mujeres y acuden menos a los } \\
\text { cuidados de salud. Son hospitalizados más } \\
\text { graves y acuden a urgencia cuando ya no } \\
\text { soportan la enfermedad. También se observó } \\
\text { que la construcción de la subjetividad } \\
\text { masculina es compleja y difícil, ya que se basa } \\
\text { en oposición a no ser una mujer, homosexual } \\
\text { o niño. }\end{array}$ \\
\hline
\end{tabular}

Tabla 5 - Caracterización de los estudios seleccionados en cuanto al tipo de análisis aplicado y resultados. (Cont.)

\begin{tabular}{lll} 
№ de los Tipo de análisis & Resultados \\
estudios aplicado & & \\
\hline
\end{tabular}

Estudio 2 El análisis de los registros que fueron tabulados y analizados cuantitativamente por la frecuencia absoluta $y$ relativa $y$ presentados en forma de tablas, cuadros y figuras a través de software de Microsoft Office Excel 2008 ß. Los datos obtenidos a través de entrevista se analizaron mediante la técnica de análisis de contenido de Bardin.

Estudio 3 El análisis de los relatos; Identificación de actitudes e interpretación de los sentidos.

Estudio 4 El análisis se basa en el método de interpretación de significados, anclándose en
Hemos tomado nota de la falta de actividades educativas y de salud sexual dirigida a los hombres, como también a través del registro documental, justificada por la baja demanda de hombres en búsqueda por este servicio, la sobrecarga de actividades de los profesionales y el predominio de los aspectos de género, reafirmando que son las mujeres quienes más acuden a los servicios de salud. También es notable la falta de capacitación del personal en la búsqueda activa de estos hombres, sobre todo en un enfoque sexual.

Fueron identificados, en este contexto, las diferentes dimensiones de la (in) visibilidad: los hombres como los blancos de las intervenciones en materia de políticas de salud pública, como los usuarios que enfrentan dificultades en la búsqueda de atención y fomentar su participación efectiva, como sujetos de atención (propio y ajeno).

En el grupo de los 201 encuestados (tabla 1), predominan las siguientes características sociales y demográficas: edad de 26 a 45 años $(36.8 \%)$, blancos $(35,5 \%)$, enseñanza primaria $(33,3 \%)$, empleados y / o por cuenta 
principios dialécticohermenéuticos. propia $(62,2 \%)$ y estar casado $(38,8 \%)$. En la caracterización, fueron utilizados - como base para la pregunta de raza / etnia, educación, empleo y estado civil - los criterios de la colección del Instituto Brasileiro de Geografia e Estatística (IBGE).

\begin{tabular}{|c|c|c|}
\hline Estudio 5 & $\begin{array}{ll}\text { El análisis de } & \text { de } \\
\text { contenido basado en } & \text { é } \\
\text { el método } & \text { de } \\
\text { interpretación } & \text { de } \\
\text { significados, } & \\
\text { anclándose } & \text { en } \\
\text { principios dialéctico- } \\
\text { hermenéuticos. }\end{array}$ & $\begin{array}{l}\text { Representación de cuidado como tarea } \\
\text { femenina, las cuestiones relacionadas con el } \\
\text { trabajo, el escaso acceso a los servicios y la } \\
\text { falta de unidades específicas para la salud del } \\
\text { hombre son las principales razones } \\
\text { expresadas por los sujetos a la baja búsqueda } \\
\text { por los servicios de salud. }\end{array}$ \\
\hline Estudio 6 & $\begin{array}{l}\text { Las informaciones } \\
\text { fueron analizadas } \\
\text { desde la perspectiva } \\
\text { teórica de las prácticas } \\
\text { discursivas y } \\
\text { producción de sentido } \\
\text { en la vida cotidiana, } \\
\text { basada en el } \\
\text { construccionismo } \\
\text { social. }\end{array}$ & $\begin{array}{l}\text { Identificado el aumento del consumo de } \\
\text { alcohol y otras drogas psicoactivas entre los } \\
\text { jóvenes, y una preferencia entre los miembros } \\
\text { de la comunidad, para usar sentar } \\
\text { conocimientos sobre el cuidado de la salud, y } \\
\text { no la red oficial del servicio, utilizándola sólo } \\
\text { en caso de empeoramiento clínico y / o dolor. }\end{array}$ \\
\hline
\end{tabular}

Tabla 5 - Caracterización de los estudios seleccionados cuanto al tipo de análisis aplicado y resultados. (Cont.)

\begin{tabular}{|c|c|c|}
\hline $\begin{array}{l}\text { № de los } \\
\text { estudios }\end{array}$ & $\begin{array}{l}\text { Tipo de } \\
\text { aplicado }\end{array}$ & Resultados \\
\hline Estudio 7 & $\begin{array}{lr}\text { El análisis } & \text { de } \\
\text { contenido de las } \\
\text { entrevistas que fueron } \\
\text { grabadas } & y \\
\text { posteriormente } & \\
\text { transcritas. } & \end{array}$ & $\begin{array}{l}\text { Se analizaron } 69 \text { entrevistas en profundidad } \\
\text { de los profesionales de la salud con formación } \\
\text { universitaria. Informes de profesionales (re) } \\
\text { producen la noción de que los servicios son } \\
\text { "espacios feminizados", que se traduce en su } \\
\text { vida cotidiana por un refuerzo de la idea del } \\
\text { cuerpo masculino como un lugar del no } \\
\text { cuidado en comparación con el cuerpo de la } \\
\text { mujer como el lugar de esta atención. Destaca } \\
\text { la representación de los profesionales sobre } \\
\text { los hombres enfocados en la fuerte presencia } \\
\text { de un modelo hegemónico de masculinidad, } \\
\text { que influye en ellos poca implicación con el } \\
\text { cuidado de la salud. }\end{array}$ \\
\hline
\end{tabular}

Estudio 8 Análisis

epidemiológico basado en datos secundarios obtenidos de informaciones nacionales disponibles en el sistema de informaciones del
Los hombres muestran situación de salud desfavorable en comparación con las mujeres, especialmente en lo que se refiere a causas violentas, hecho claramente expresado en los datos de mortalidad de Brasil, en el período 1991-2005. 
SUS- DATASUS que presenta el perfil de mortalidad de los hombres en Brasil, en el período 1991-2005.
Estudio Análisis utilizando el 9 paquete estadístico Statal, buscando considerar el diseño de muestreo de PNAD (con la variable v4617 definiendo los estratos, el v4618 limitando las unidades primarias de muestreo y los pesos que dan la probabilidad de selección de cada observación).

Estudio El análisis temático de 10 las entrevistas y registros etnográficos se basó en los referenciales de género y en estudios del trabajo en salud.
Se constata que, de 1998 a 2008, la parcela de la población brasileña que necesita asistencia sanitaria durante las dos semanas anteriores a la encuesta fue de alrededor de $17 \%$, mientras que la parcela con necesidad de salud insatisfecha se redujo de $3,5 \%$ a 2 $9 \%$. También se ha cambiado el perfil de las razones que la gente elige para justificar no haber buscado atención médica. El porcentaje de los que afirmaban la falta de dinero se redujo, aunque sea la razón más escogida, aumentando el porcentaje de los que dicen que las limitaciones y fallos del sistema de salud, como el tiempo de espera y la falta de profesionales o servicios. Bajos ingresos o nivel de educación, la residencia en las regiones más pobres del país o en área rural, ser negro, ser hombre, ser adulto, estar ocupado, vivir con otras personas con necesidades no satisfechas, no hacer consulta médica durante al menos un año y no tener ningún plan de la salud es, entre otros, características que aumentan la propensión a no satisfacer la necesidad de buscar atención médica.

Los resultados muestran como la medicalización de las necesidades de salud marcan usuarios, profesionales y servicios, ocultando las cuestiones relacionadas con la masculinidad.

Tabla 5 - Caracterización de los estudios seleccionados en cuanto al tipo de análisis aplicado y resultados. (Cont.)

\begin{tabular}{|c|c|c|}
\hline $\begin{array}{l}\text { № de los } \\
\text { estudios }\end{array}$ & $\begin{array}{l}\text { Tipo de análisis } \\
\text { aplicado }\end{array}$ & Resultados \\
\hline & $\begin{array}{l}\text { Análisis temático de } \\
\text { contenido, según los } \\
\text { criterios establecidos } \\
\text { por Bardin. Para la } \\
\text { demostración de los } \\
\text { datos se utilizaron } \\
\text { árboles de asociación } \\
\text { de los sentidos. }\end{array}$ & $\begin{array}{l}\text { Los resultados muestran las diferencias entre } \\
\text { hombres y mujeres en lo que respecta a la } \\
\text { atención médica. Las mujeres son } \\
\text { consideradas como más cuidadosas y los } \\
\text { hombres son más vulnerables a los problemas } \\
\text { psicosociales, tales como el sexismo, las } \\
\text { dificultades para asumir la enfermedad en el } \\
\text { trabajo y la dificultad en el acceso a servicios } \\
\text { de salud. La prevención del cáncer de próstata }\end{array}$ \\
\hline
\end{tabular}


fue el aspecto más señalado cuando la preocupación es la salud.

Estudio Análisis de contenido 12 para tratar los datos.
Estudio El análisis se basa en 13 el método de interpretación significados, guiado por la hermenéutica filosófica.
En el habla de los sujetos se evidenció que los hombres buscan menos los servicios debido a la incompatibilidad con la jornada laboral. $\mathrm{Y}$, sin embargo, según la percepción de los sujetos se sienten avergonzados de buscar ayuda porque esta postura choca con la cultura andocéntrica. Se ha verificado que la mayor parte de los sujetos desconocen la Política Nacional de Atención Integral a la Salud de los Hombres.

Los principales problemas son: las infecciones de transmisión sexual, la prevención del cáncer de próstata y los problemas relacionados con la erección. Hay un enfoque profesional superficial, abreviado y anclado en el parámetro de medicalización.

Estudio Análisis de contenido, Los resultados revelaron opiniones 14 según Bardin.

heterogéneas sobre los servicios ofrecidos por la Estrategia, con un predominio de juicios negativos, debido a la dificultad de obtener la consulta médica y el retraso en los exámenes, además de la escasez de profesionales y médicos expertos en servicios de atención primaria.

Estudio Análisis temático de Encontramos una diversidad de modelos de 15 contenido, desde la lectura completa del material. masculinidad que pueden definir diferentes formas de pensar en el cuidado de la salud de los hombres. Se observó que las cuestiones tales como el trabajo, la sexualidad, la estructura del cuerpo, las relaciones con las mujeres y los cambios en las relaciones de género son temas importantes para los hombres y se debe considerar en los servicios de salud.

Fuente: $\quad$ Artículos de las bases de datos online de la Biblioteca Virtual de Saúde (BVS).

El análisis de la clasificación de las evidencias de los artículos se basa en la propuesta de los autores para clasificar la evidencia en seis niveles (31), de la siguiente manera: Nivel I, representada por los estudios que incluyen el meta-análisis de múltiples estudios controlados, Nivel II, consiste en estudios individuales experimentales; Nivel III, son los estudios casi-experimentales, como el ensayo clínico aleatorizado, el grupo experimental, como ensayo clínico aleatorio, de grupo único pre y post-test, así como series de tiempo o de casos y controles; Nivel IV, son estudios 
no experimentales, como investigación descriptiva, correlacional y comparativa, con enfoque cualitativo y estudios de casos; los estudios del Nivel V presentan datos de la evaluación de programas obtenidos de manera sistemática y, finalmente, el Nivel VI es representado por los estudios que tienen opiniones de expertos, relatos de experiencia, el consenso, reglamentos y leyes.

Este análisis se muestra en la Tabla 6, que muestra que la gran mayoría de los 15 estudios de investigación presenta evidencia de nivel IV, que se caracteriza como estudios no experimentales, como el enfoque cualitativo descriptivo, correlativo y comparativos y los estudios de caso. Además de la clasificación del grado de comprobación científica de los artículos utilizados en esta revisión integradora, la tabla 6 también presenta las conclusiones y recomendaciones formuladas por los autores.

Tabla 6 - Caracterización de los estudios en cuanto a la conclusión, recomendaciones de los autores y nivel de evidencia.

\begin{tabular}{|c|c|c|c|}
\hline $\begin{array}{l}\text { № de } \\
\text { los } \\
\text { estudios }\end{array}$ & Conclusiones & $\begin{array}{l}\text { Recomendaciones de } \\
\text { los autores }\end{array}$ & $\begin{array}{ll}\text { Nivel } & \text { de } \\
\text { evidencia } & \end{array}$ \\
\hline $\begin{array}{l}\text { Estudio } \\
1\end{array}$ & $\begin{array}{l}\text { Parece que la salud del } \\
\text { hombre ha sido poco } \\
\text { considerada por las políticas } \\
\text { de salud pública que al final } \\
\text { resultan en una falta de } \\
\text { atención de los servicios de } \\
\text { salud. }\end{array}$ & $\begin{array}{l}\text { Es necesario un } \\
\text { replanteamiento sobre } \\
\text { todas las cuestiones } \\
\text { planteadas en relación } \\
\text { con la salud del } \\
\text { hombre. }\end{array}$ & 5 \\
\hline $\begin{array}{l}\text { Estudio } \\
2\end{array}$ & $\begin{array}{l}\text { Bajo este enfoque, para } \\
\text { aumentar la promoción de la } \\
\text { salud de las personas en lo } \\
\text { que respecta a las IST y el } \\
\text { VIH, debe haber actividades } \\
\text { educativas destinadas a } \\
\text { promover la salud, la } \\
\text { prevención y el tratamiento } \\
\text { de la misma para la } \\
\text { población en su conjunto y } \\
\text { también para profesionales } \\
\text { de la salud, que deben tener } \\
\text { la formación técnica de } \\
\text { acuerdo con sus } \\
\text { asignaciones. }\end{array}$ & $\begin{array}{l}\text { Es muy importante la } \\
\text { capacitación del grupo } \\
\text { de profesionales que } \\
\text { no tienen universidad, } \\
\text { ya que son el enlace } \\
\text { entre el equipo de } \\
\text { salud y la comunidad, } \\
\text { están a la vanguardia } \\
\text { de la atención y son } \\
\text { los que más conocen } \\
\text { la comunidad asistida. }\end{array}$ & 4 \\
\hline
\end{tabular}


Tabla 6 - Caracterización de los estudios en cuanto a la conclusión, recomendaciones de los autores y nivel de evidencia. (Cont.)

\begin{tabular}{|c|c|c|c|}
\hline $\begin{array}{l}\text { № de } \\
\text { los } \\
\text { estudios }\end{array}$ & Conclusiones & $\begin{array}{l}\text { Recomendaciones de } \\
\text { los autores }\end{array}$ & $\begin{array}{l}\text { Nivel } \\
\text { evidencia }\end{array}$ \\
\hline $\begin{array}{l}\text { Estudio } \\
3\end{array}$ & $\begin{array}{l}\text { Fueron identificados en este } \\
\text { contexto las diferentes } \\
\text { dimensiones de la (in) } \\
\text { visibilidad: los hombres } \\
\text { como los objetivos de las } \\
\text { intervenciones en materia de } \\
\text { políticas de salud pública, } \\
\text { cómo los usuarios enfrentan } \\
\text { dificultades en la búsqueda } \\
\text { de atención y fomentar su } \\
\text { participación efectiva, como } \\
\text { sujetos de atención (propio y } \\
\text { ajeno). }\end{array}$ & $\begin{array}{l}\text { El estudio pone de } \\
\text { relieve la importancia } \\
\text { de los estudios de } \\
\text { género y su relación } \\
\text { con la salud, en la } \\
\text { medida en que se } \\
\text { discute la producción } \\
\text { de las desigualdades } \\
\text { sociales (re) } \\
\text { producidas por las } \\
\text { desigualdades de } \\
\text { género presentes en lo } \\
\text { imaginario y en los } \\
\text { servicios de salud. }\end{array}$ & 4 \\
\hline $\begin{array}{l}\text { Estudio } \\
4\end{array}$ & $\begin{array}{l}\text { Llegamos a la conclusión de } \\
\text { que los hombres usuarios } \\
\text { idealizan y reclaman una } \\
\text { forma particular de la } \\
\text { atención considerada buena } \\
\text { y que, en principio, podría } \\
\text { servir también para discutir } \\
\text { el cuidado de las mujeres. } \\
\text { Sin embargo, a causa de la } \\
\text { socialización que los } \\
\text { hombres y las mujeres } \\
\text { experimentan, son } \\
\text { reforzadas las diferencias } \\
\text { entre ser hombre y ser } \\
\text { mujer. }\end{array}$ & $\begin{array}{l}\text { Por otra parte, tanto en } \\
\text { lo que respecta a los } \\
\text { profesionales como a } \\
\text { los usuarios, esa } \\
\text { misma segmentación } \\
\text { por género puede } \\
\text { contribuir para que se } \\
\text { arrecie la imposibilidad } \\
\text { de hacer frente a las } \\
\text { características de } \\
\text { específicas } \\
\text { hombres y mujeres en } \\
\text { cuanto a las demandas } \\
\text { de salud. }\end{array}$ & 4 \\
\hline $\begin{array}{l}\text { Estudio } \\
5\end{array}$ & $\begin{array}{l}\text { Llegamos a la conclusión, } \\
\text { entre otras cosas, que el } \\
\text { imaginario social, que ve al } \\
\text { hombre como un ser } \\
\text { invulnerable, contribuye para } \\
\text { que él se cuide menos y se } \\
\text { exponga más a situaciones } \\
\text { de riesgo. }\end{array}$ & No hay. & 4 \\
\hline $\begin{array}{l}\text { Estudio } \\
6\end{array}$ & $\begin{array}{l}\text { Señala la necesidad de } \\
\text { ampliar el pensamiento } \\
\text { acerca de la masculinidad, } \\
\text { en vista del compromiso con } \\
\text { la salud del hombre. }\end{array}$ & $\begin{array}{l}\text { De la misma manera } \\
\text { que otras políticas } \\
\text { públicas dirigidas a } \\
\text { grupos sociales } \\
\text { discriminados son hitos } \\
\text { políticos, las políticas } \\
\text { de salud deben entrar }\end{array}$ & 4 \\
\hline
\end{tabular}


en vigor con el objetivo

de mejorar el SUS, en

particular, desde sus

principios básicos, y no

como una carga

adicional en un

sistema sobrecargado.

Tabla 6 - Caracterización de los estudios en cuanto a la conclusión, recomendaciones de los autores y nivel de evidencia. (Cont.)

\begin{tabular}{|c|c|c|c|}
\hline $\begin{array}{l}\text { № de } \\
\text { los } \\
\text { estudios }\end{array}$ & Conclusiones & $\begin{array}{l}\text { Recomendaciones de } \\
\text { los autores }\end{array}$ & $\begin{array}{ll}\text { Nivel } & \text { de } \\
\text { evidencia } & \end{array}$ \\
\hline $\begin{array}{l}\text { Estudio } \\
7\end{array}$ & $\begin{array}{l}\text { La existencia de un modelo } \\
\text { estereotipado de género } \\
\text { implica la (re) producción de } \\
\text { las desigualdades entre } \\
\text { hombres y mujeres en el } \\
\text { cuidado de la salud y } \\
\text { compromete la visibilidad de } \\
\text { otros significados y } \\
\text { expresiones de las } \\
\text { identidades de género. }\end{array}$ & No hay. & 4 \\
\hline $\begin{array}{l}\text { Estudio } \\
8\end{array}$ & $\begin{array}{l}\text { Los hombres muestran una } \\
\text { situación de salud } \\
\text { desfavorable comparado con } \\
\text { la salud de las mujeres, } \\
\text { especialmente en lo que se } \\
\text { refiere a causas violentas, } \\
\text { hecho expreso claramente } \\
\text { en los datos de mortalidad } \\
\text { de Brasil, en el período de } \\
1991 \text { a } 2005 \text {. Nuestra } \\
\text { hipótesis es que el } \\
\text { desgarramiento del tejido } \\
\text { social - la colonización del } \\
\text { mundo de la vida con la } \\
\text { pérdida de sentido, las } \\
\text { anomalías y la consiguiente } \\
\text { psicopatología - engendra la } \\
\text { violencia que prolifera en las } \\
\text { sociedades modernas. El } \\
\text { hombre, en virtud de los } \\
\text { rasgos culturales de su } \\
\text { masculinidad, sería mucho } \\
\text { más vulnerable a las } \\
\text { influencias de ese contexto, } \\
\text { al mismo tiempo que se } \\
\text { reproducen y refuerzan. }\end{array}$ & $\begin{array}{l}\text { Para la comprensión, } \\
\text { sin embargo, más } \\
\text { profunda de estas } \\
\text { cuestiones, bien como } \\
\text { las posibilidades de } \\
\text { encontrar mecanismos } \\
\text { de adaptación son } \\
\text { necesarios r más } \\
\text { estudios r para } \\
\text { establecer, de una } \\
\text { manera basada en } \\
\text { principios, los temas } \\
\text { de esta cultura tan } \\
\text { arraigada de la } \\
\text { masculinidad. }\end{array}$ & 4 \\
\hline
\end{tabular}




\begin{tabular}{|c|c|c|}
\hline & $\begin{array}{l}\text { Bajos ingresos o nivel de } \\
\text { educación, la residencia en } \\
\text { las regiones más pobres del } \\
\text { país o en área rural, ser } \\
\text { negro, ser hombre, ser } \\
\text { adulto, estar ocupado, vivir } \\
\text { con otras personas con } \\
\text { necesidades no satisfechas, } \\
\text { no hacer consultas médicas } \\
\text { durante al menos un año y } \\
\text { no tener ningún plan de la } \\
\text { salud son, entre otras, } \\
\text { características que } \\
\text { aumentan la propensión a no } \\
\text { satisfacer la necesidad de } \\
\text { buscar atención médica. }\end{array}$ & $\begin{array}{l}\text { Se necesitará más } \\
\text { investigación de la } \\
\text { necesidad de salud } \\
\text { insatisfecha por no } \\
\text { buscar atención para } \\
\text { que pueda tener una } \\
\text { mejor comprensión de } \\
\text { sus causas. Los } \\
\text { resultados serán de } \\
\text { utilidad para que a } \\
\text { través de un mejor } \\
\text { conocimiento de la } \\
\text { diversidad de las } \\
\text { situaciones, se } \\
\text { establezcan an } \\
\text { estrategias específicas } \\
\text { para la inclusión, con } \\
\text { el objetivo de que, } \\
\text { según lo dispuesto en } \\
\text { la Constitución, el } \\
\text { acceso a los servicios } \\
\text { de salud sea } \\
\text { efectivamente } \\
\text { universal. }\end{array}$ \\
\hline
\end{tabular}

\begin{tabular}{|c|c|c|c|}
\hline $\begin{array}{l}\text { № de } \\
\text { los } \\
\text { estudios }\end{array}$ & Conclusiones & $\begin{array}{l}\text { Recomendaciones de } \\
\text { los autores }\end{array}$ & $\begin{array}{l}\text { Nivel } \\
\text { evidencia }\end{array}$ \\
\hline $\begin{array}{l}\text { Estudio } \\
10\end{array}$ & $\begin{array}{l}\text { Caracterizada como } \\
\text { atención primaria para las } \\
\text { mujeres, reproduciendo en el } \\
\text { funcionamiento de los } \\
\text { servicios y en la actuación } \\
\text { profesional desigualdades } \\
\text { de género, que para las } \\
\text { mujeres hay la disciplina del } \\
\text { cuidado, mientras que para } \\
\text { los hombres, falta asistencia } \\
\text { y cuidado. }\end{array}$ & $\begin{array}{l}\text { También es importante } \\
\text { ampliar la producción } \\
\text { científica en este } \\
\text { campo, enriqueciendo } \\
\text { el debate. }\end{array}$ & 4 \\
\hline $\begin{array}{l}\text { Estudio } \\
11\end{array}$ & $\begin{array}{l}\text { Las mujeres son } \\
\text { consideradas como más } \\
\text { cuidadosas y los hombres } \\
\text { son más vulnerables a los } \\
\text { problemas psicosociales, } \\
\text { tales como el sexismo, las } \\
\text { dificultades para asumir la } \\
\text { enfermedad en el trabajo y la } \\
\text { dificultad en el acceso a } \\
\text { servicios de salud. La }\end{array}$ & $\begin{array}{l}\text { Se cree, por lo tanto, } \\
\text { que el conocimiento de } \\
\text { los factores } \\
\text { psicosociales que } \\
\text { influyen en la decisión } \\
\text { de los hombres en el } \\
\text { momento de acudir a } \\
\text { los servicios de APS, } \\
\text { puede contribuir a } \\
\text { proponer cambios }\end{array}$ & 4 \\
\hline
\end{tabular}


prevención del cáncer de próstata fue el aspecto más señalado cuando preocupación es la salud.

institucionales que

sean capaces de atraer a este público e interferir en las construcciones culturales vinculadas a la atención de la salud y las percepciones de los hombres en relación a esa atención. Lo que queremos lograr es incitar a los hombres a incorporar nuevas prácticas más saludables a su forma de vida.

Estudio 12
En el habla de los sujetos estuvo evidente que los hombres buscan menos los servicios debido a la incompatibilidad con la jornada laboral. $Y$ aún, según la percepción de ellos, se sienten constreñidos a buscar ayuda porque este enfoque choca con la cultura andocréntrica. Hemos verificado que la mayoría de los sujetos desconocían la Política Nacional de Atención Integral a la Salud de los Hombres.
Se sugiere que se imparta una capacitación de las enfermeros, y que los servicios tengan infraestructura física y de personal para garantizar una atención de calidad.

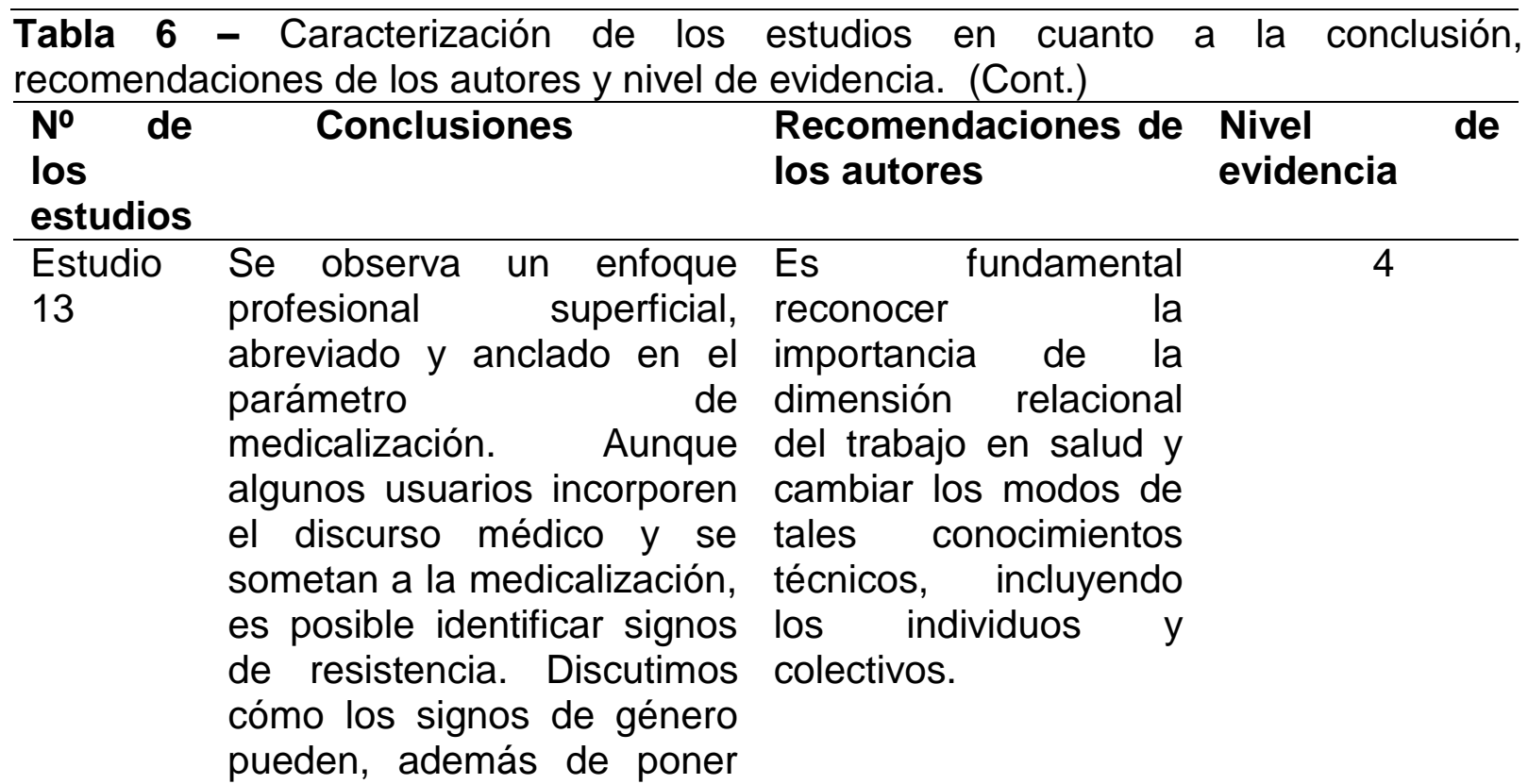




\begin{tabular}{|c|c|c|c|}
\hline & $\begin{array}{l}\text { barreras en el cuidado de la } \\
\text { salud, provocar la } \\
\text { construcción de relaciones } \\
\text { dialógicas entre los } \\
\text { profesionales y los usuarios } \\
\text { hombres. }\end{array}$ & & \\
\hline $\begin{array}{l}\text { Estudio } \\
14\end{array}$ & $\begin{array}{l}\text { Se constató la necesidad de } \\
\text { contar con de las } \\
\text { reestructuración de las } \\
\text { Unidades Básicas de Salud, } \\
\text { así como el trabajo de los } \\
\text { profesionales, con el fin de } \\
\text { satisfacer la demanda de } \\
\text { salud de la población } \\
\text { masculina. }\end{array}$ & $\begin{array}{l}\text { Se cree que } \\
\text { reestructurar las UBS } \\
\text { con el fin de ampliar su } \\
\text { horario de atención } \\
\text { para la noche crearía } \\
\text { oportunidades para la } \\
\text { búsqueda de atención } \\
\text { tanto de los incluidos } \\
\text { en el mercado laboral } \\
\text { formal, como de los } \\
\text { trabajadores que a } \\
\text { autónomos queciben } \\
\text { menudo la por la } \\
\text { ingresos los } \\
\text { cantidad de horas } \\
\text { trabajadas. Con eso se } \\
\text { espera que la } \\
\text { búsqueda de los } \\
\text { hombres por las } \\
\text { instituciones básicas } \\
\text { de salud aumente y, } \\
\text { por consiguiente, } \\
\text { garantice mayor } \\
\text { adherencia de ellos en } \\
\text { tratamientos y } \\
\text { acciones preventivas. }\end{array}$ & 4 \\
\hline $\begin{array}{l}\text { Estudio } \\
15\end{array}$ & $\begin{array}{l}\text { Se observó que las } \\
\text { cuestiones tales como el } \\
\text { trabajo, la sexualidad, la } \\
\text { estructura del cuerpo, las } \\
\text { relaciones con las mujeres y } \\
\text { los cambios en las } \\
\text { relaciones de género son } \\
\text { temas importantes para los } \\
\text { hombres y se debe } \\
\text { considerar en los servicios } \\
\text { de salud. }\end{array}$ & $\begin{array}{l}\text { Temas como el trabajo } \\
\text { y la sexualidad, por } \\
\text { ejemplo, deben ser } \\
\text { considerados en las } \\
\text { discusiones sobre la } \\
\text { prevención y } \\
\text { promoción de la salud, } \\
\text { desde un punto de } \\
\text { vista que permita } \\
\text { aumentar el campo de } \\
\text { la percepción de las } \\
\text { relaciones entre el } \\
\text { género y la salud. Con } \\
\text { ello, se puede } \\
\text { conseguir un mayor } \\
\text { cuestionamiento de } \\
\text { estos temas, como } \\
\text { también luchar contra }\end{array}$ & 4 \\
\hline
\end{tabular}


la falta de equidad en

la salud $y$ en los

géneros.

\section{DISCUSIÓN}

Después de la presentación de las características de los 15 artículos seleccionados, realizada de forma descriptiva, serán presentadas las discusiones pertinentes a los resultados.

Mediante el establecimiento de una visión de la salud del hombre brasileño, se observa que esta cuestión había sido poco discutida en comparación con el tema de la salud de la mujer. Parece que desde hace años, los hombres permanecieron invisibles para el sector de la salud pública; sólo recientemente se ven como personas, como las mujeres y los niños, que también se enferman y prueba de ello fue la implementación de la Política Nacional de Atención Integral a la Salud del Hombre 2008.

El propósito de esta revisión integradora es reunir y sintetizar las evidencias disponibles en la literatura sobre el tema investigado. Procuramos articular los resultados del análisis de los artículos que se encuentran en las bases de datos con el fin de responder a la pregunta de investigación de este estudio que es identificar los retos de la Política Nacional de Atención Integral a la Salud del Hombre, implementada desde 2008 por el gobierno de Brasil.

Una revisión de la literatura concluye que hay una ausencia de los varones en las UBS, este hallazgo proviene de la pregunta: ¿los hombres no se enferman o no tienen la atención necesaria por parte del sector de la salud pública?

Esta diferencia no se debe pensar únicamente como una falta de responsabilidad de los hombres con su salud o específicamente como un fracaso en los modelos de organización de la atención primaria a la salud y, por lo tanto, los 15 artículos seleccionados en esta revisión se discuten en torno a dos temas relacionados con los retos y obstáculos encontrados por el MS para la implementación de la PNAISH, y una categoría que indica las acciones sugeridas por los autores, que deben ser implementadas con el objetivo de la adhesión de los hombres a la PNAISH, a saber: A) los factores intrínsecos a los varones, B ) los factores extrínsecos a los varones, y C) las acciones de promoción, prevención y atención a la salud dirigida a los hombres, que se presentan a continuación:

\section{A) Factores intrínsecos a los hombres}

La situación de salud de los hombres claramente desfavorable hacia las mujeres se evidencia tanto por el aumento de la mortalidad en todos los grupos de edad, como por su manera específica de hacer frente a la atención de la salud, como lo demuestra su ausencia en los servicios de atención primaria, su baja adhesión y demora en la búsqueda de atención, con el consiguiente deterioro de su salud ${ }^{(10)}$.

La resistencia de los hombres a buscar médico o profesional de la salud al sentir necesidad puede tener antecedentes culturales y estar asentada en las relaciones de género, incluyendo la mayor participación en el mercado laboral, además de la dificultad de acceso relacionada con el período de funcionamiento de 
establecimientos de salud, a pesar de que actualmente gran parte de las mujeres también tienen una importante participación en el mercado de trabajo y aún así asisten con mayor frecuencia a los servicios de salud ${ }^{(26)}$.

Hay muchas hipótesis que justifican la escasa presencia masculina en los servicios de atención primaria a la salud. La ausencia de los hombres o su invisibilidad en estos servicios es parte de la característica de la identidad masculina en relación con su proceso de socialización. Para los autores, la identidad masculina está asociada con la devaluación del auto-cuidado y la preocupación de la salud casi inexistente ${ }^{(2)}$.

La deficiencia de la atención a la salud de los hombres puede estar relacionada con reflejos de valores de la sociedad con respecto a la percepción de los modelos de masculinidad construido en la subjetividad que implica atributos como la fuerza, dominio y machismo. Esta percepción se atribuye en todos los ámbitos sociales, en particular en el ámbito de la salud, donde las políticas públicas no han resultado de modo satisfactorio las necesidades de salud de ese porcentaje poblacional ${ }^{(30)}$.

El hombre es prisionero de algunos aspectos culturales como la virilidad, la fuerza y la invulnerabilidad, que dificulta la visión, incluso la adopción de prácticas de autocuidado, ya que, buscar atención médica, desde el punto de vista preventivo, se puede asociar a la debilidad, el miedo y la inseguridad que lo acerca a las representaciones del universo femenino, lo que sugiere posibles dudas sobre la masculinidad socialmente instituida para el hombre ${ }^{(12)}$.

Un factor que está relacionado con este tema es la consideración de que es difícil, en este grupo, reconocer sus propias necesidades de salud, cultivar el pensamiento que rechaza la posibilidad de enfermarse ${ }^{(29)}$.

En la sociedad los hombres son considerados como el sexo fuerte y las mujeres como pertenecientes al sexo débil y esto los definen como personas, determinando que el hombre es fuerte, no sólo en el aspecto físico, sino también desde la dimensión emocional que implica el prejuicio de que el hombre no necesita ser cuidado ${ }^{(24)}$.

Sobre la percepción de los usuarios de la salud es que, aunque colocado en diferentes contextos sociales, y, aunque los hombres tengan las mismas necesidades de salud que las mujeres, ellos presentan una serie de dificultades en la búsqueda de servicios y prefieren retrasar al máximo la búsqueda de la asistencia y sólo cuando ya no pueden hacer frente a solas con sus síntomas ${ }^{(27)}$.

Uno de los principales obstáculos para la promoción de la salud de los hombres, como se repite varias veces durante el proceso de construcción de la nueva política de salud del hombre, es precisamente la centralidad de la idea de que son más vulnerables a los problemas psicosociales, tales como el sexismo, dificultades para asumir la enfermedad en el trabajo y la dificultad en el acceso a los servicios de salud $^{(28)}$.

No hay que olvidar que existe una diversidad de modelos de masculinidad que pueden definir diferentes formas de pensar en el cuidado de la salud de los hombres, ya que las cuestiones relacionadas con el trabajo, la sexualidad, la estructura del cuerpo, las relaciones con las mujeres y los cambios en las relaciones de género son temas importantes para los hombres y deben ser considerados en los servicios de salud $^{(17)}$. 
Un estudio reciente realizado en una comunidad pesquera en el noreste de Brasil sobre el uso de los servicios de atención primaria de su región, los autores concluyeron que hay una preferencia entre los miembros de la comunidad para sentar conocimientos sobre el cuidado de la salud, recurriendo a la red oficial de asistencia sólo en caso de empeoramiento de la estructura y / o dolor. Como recomendación, los autores señalan la necesidad de ampliar las reflexiones sobre la masculinidad, buscando el compromiso con la salud del hombre ${ }^{(9)}$.

\section{B) Factores extrínsecos a los hombres}

En la literatura analizada es casi unánime la conclusión de los autores que reconocen las UBS como responsables de la dificultad de acceso masculino a los servicios de salud. Para algunos autores, el problema está relacionado con la pérdida de tiempo en las colas de espera para la asistencia o por el hecho de que las UBS representan para el hombre un espacio feminizado, frecuentado principalmente por mujeres y compuesto por un equipo de profesionales capacitados, en su mayoría, también por mujeres ${ }^{(5,2)}$.

Esta condición crea la impresión de que los hombres no pertenecen al espacio de las UBS, ya que no ofrecen programas o actividades específicamente para la población masculina y todo parece causar una dificultad de la formación de un vínculo que una las necesidades de salud de la población masculina y la organización de las prácticas de salud de las unidades de atención primaria, aunque algunos autores ${ }^{(12)}$ lleguen a la conclusión de que hay pocos estudios en la literatura sobre estos temas.

Autores $^{(15)}$ estudiaron los conceptos de género y masculinidad de profesionales sanitarios de Atención Primaria a la Salud (APS) en cuatro estados del país, llegaron a la conclusión de que tales servicios son espacios feminizados, lo que se traduce en su vida cotidiana por un refuerzo de la idea del cuerpo masculino como parte de la no atención en contraposición al cuerpo de la mujer como parte de esta atención, destacando el perfil de los profesionales sobre los hombres que se centran en la fuerte presencia de un modelo hegemónico de masculinidad, que influye en la poca implicación con el cuidado de la salud.

El ejemplo de las USB, como proveedores de atención primaria de salud son espacios con características estrictamente femeninas, se puede ver a través de la amplia difusión de carteles producidos por el Ministerio de Salud, la transmisión de mensajes que promueven la lactancia materna, el cuidado prenatal y prevención de enfermedades de transmisión sexual VIH / SIDA, con la excepción de algunos sobre el uso correcto del condón y sobre la lepra ${ }^{(5)}$.

También es importante tener en cuenta que los hombres de alguna manera se han resistido a la medicalización, lo que refuerza la necesidad de la participación de estos sujetos en la construcción de la atención prestada por los servicios de salud, como ocurre en tales espacios una invisibilidad de ellos ${ }^{(2)}$.

La ausencia de programas y atención dirigidos a los hombres es responsable de la invisibilidad de ellos en entornos sanitarios. Los autores concluyen que la dificultad de los hombres para acceder a los servicios de salud o de ser acogido en sus demandas en estas áreas se debe a la actitud y las expectativas de los profesionales de la salud al creer que el hombre no cuida de sí ni de los demás y por lo tanto no son estimulados a las prácticas de prevención y promoción de la salud ${ }^{(5)}$. 
Esta conclusión también es parte del estudio de otros autores ${ }^{(17)}$, al afirmar que los hombres reprimen sus necesidades de salud y tienen dificultades para expresarse, acudiendo menos que las mujeres a los servicios de salud, a menudo motivados por el hecho de que los servicios disponibles en la atención primaria están dirigidos principalmente a las mujeres, niños y ancianos.

Sin embargo, los hombres buscan poco los servicios de salud debido a la incompatibilidad con el horario de jornada laboral y, según lo percibido por los sujetos, se sienten avergonzados de buscar ayuda porque este enfoque choca con la cultura machista ${ }^{(29)}$.

La conclusión de Couto et $\mathrm{al}^{(5)}$ es similar al reciente trabajo de Gomes et al ${ }^{(18)}$ en el que los autores tuvieron como objetivo analizar la visión de los usuarios sobre la atención que reciben los hombres en el cuidado de la salud básica. Estos autores encontraron que las recomendaciones de los usuarios traen demandas que se relacionan principalmente con las lagunas en los servicios para promover una atención específicamente dirigida a los hombres.

Autores $^{(25)}$ afirman que la responsable de la baja procura de los hombres por el servicio es la sobrecarga de actividades de los profesionales y la falta de preparación de los mismos en la búsqueda activa de estos hombres.

El hombre tiene una comprensión amplia del auto cuidado, sufre las consecuencias de todo lo que está a su alrededor, por lo tanto, el género, para establecer relaciones sociales y el estado de la percepción del mundo de los sujetos, puede promover mecanismos que podrían dar lugar a la desigualdad entre hombres y mujeres en el cuidado de la salud todos los días ${ }^{(15)}$.

Un reciente estudio tuvo como objetivo identificar los puntos de vista de los hombres sobre la atención recibida en la Estrategia Salud de la Familia (ESF). Los resultados revelaron opiniones heterogéneas sobre los servicios ofrecidos por la ESF, la mayor demanda fue la dificultad en obtener consulta médica y el retraso en los exámenes, además de la escasez de profesionales médicos y expertos en servicios de atención primaria $^{(30)}$.

En opinión de los autores ${ }^{(29)}$, hay poca evidencia publicada sobre la adhesión masculina en los servicios de salud, por lo que no se puede concluir que los programas de salud específicos para los hombres son mejores que el programa generalista.

\section{C) Promoción, prevención y atención de salud dirigida a los hombres.}

La política pública no ofrece a los hombres, de manera eficiente, los servicios de atención de conformidad con sus necesidades, refuerza los prejuicios sociales ${ }^{(24)}$.

En un intento de reducir la discapacidad de dicho cuidado, surgió la PNAISH que pretende llegar a cerca de 40 millones de hombres (25 a 59 años) con el fin de cambiar la cultura en relación con la promoción de la prevención y atención de salud del hombre, sin embargo, de acuerdo con Silva et al (29), esto sólo es posible si hay una capacitación de los enfermeros e infraestructura física de los servicios y de personal capacitado para garantizar una atención de calidad a los hombres. 
La valoración de diversas informaciones y prácticas, con la esperanza de hacer un enfoque completo y resolver el problema permite la creación de vínculos que asocian la confianza y la ética, la obligación y el respeto, normas que compiten e integran los principios y directrices de la Política Nacional de Desarrollo Integral para la Salud del Hombre ${ }^{(25)}$.

Algunos temas, como el trabajo y la sexualidad, se deben observar en los debates de la prevención y promoción de la salud, con el fin de obtener las respuestas que permitan ampliar el campo de percepción de las relaciones entre el género y salud ${ }^{(17)}$.

Algunas sugerencias tienen como punto de inicio la reorganización de las instituciones básicas de salud para conseguir más agilidad en el enrutamiento de los usuarios para una atención de mayor complejidad, como, por ejemplo, ampliar su horario de apertura a la noche ${ }^{(30)}$.

En este sentido, la importancia de reconocer la dimensión relacional del trabajo de salud y el cambio de los modos de la actual corriente de conocimientos y la atención, sobre todo para los individuos como sujetos o colectivamente ${ }^{(2)}$.

Todavía hay necesidades de producción de cuidados cuanto a la remodelación de su respuesta asistencial cuando se la quiere completa, debido a que la complejidad de la atención primaria no se superponen a las patologías y deben reconstruir la producción de atención ${ }^{(27)}$.

Hay cuidados que deben ser parte del trabajo realizado por un equipo multiprofesional, que a través del conocimiento multidisciplinario debe tratar de comprender e intervenir en el proceso salud/enfermedad en general, especialmente en relación con la salud del hombre ${ }^{(28)}$.

Para obtener este conocimiento se requiere más investigación sobre la necesidad de salud insatisfecha y por la no búsqueda de atención en centros de salud por parte de los hombres, de modo que se pueda conseguir una mejor comprensión de sus causas (26).

La comprensión más profunda de las cuestiones relativas a la baja demanda de los servicios de salud de los hombres, así como las posibilidades de encontrar mecanismos de afrontamiento de la cuestión radica en la realización de más estudios para establecer de modo fundamentado tematizar la cultura tan extremadamente enraizada en la masculinidad ${ }^{(10)}$.

Aunque algunos autores ${ }^{(12)}$ argumentan que en la literatura sobre este tema es posible haya una contradicción entre los datos epidemiológicos (que ven al hombre como más vulnerable que las mujeres) y el sentido común (que ve al hombre como más invulnerable, pero todavía puede alimentar el debate con el fin de demostrar que estas ideas, aparentemente contradictorias, se complementan entre sí).

En especial, los estudios de satisfacción de los hombres, que pueden contribuir al desarrollo de futuras investigaciones para articular la dimensión de género en el tema de la calidad en el acceso y la recepción de los usuarios en los servicios ${ }^{(18)}$.

Las estrategias implementadas actualmente no están produciendo eficazmente acciones que incorporen la atención a los hombres y todavía están fuera del alcance de los servicios en APS la incorporación y la eficacia de la suposición de género sobre 
masculinidad, que aboga por la expansión en la comprensión de los hombres como sujetos concretos y particulares en los diferentes significados atribuidos a la masculinidad y a las interacciones sociales de estos con la sociedad ${ }^{(15)}$.

Persistir en los patrones tradicionales de atención impide la renovación de los servicios hacia una atención cada vez más completa, por lo que es difícil de llevar a la totalidad de los que se enfrentan los temas de género y salud ${ }^{(5)}$.

Las manifestaciones de la masculinidad hegemónica, presentes en los discursos de los hombres, lanzan retos para la inclusión de esta población en el sistema de salud y para que las políticas de salud deben entrar en vigor con el objetivo de mejorar el SUS, en particular, desde sus principios rectores, y no como una carga adicional en un sistema sobrecargado ${ }^{(9)}$.

Es a través de actividades educativas en la comunidad que se posibilita el rescate del universo masculino y se establecena mecanismos de proximidad con la misma, con el fin de proporcionar una mayor apertura por parte de los profesionales, posibilitando una mayor aproximación a este usuario, que facilitará el cumplimiento y asegurará la llegada del hombre al servicio de salud pública ${ }^{(25)}$.

\section{CONSIDERACIONES FINALES}

Un resumen de los estudios seleccionados en esta revisión integradora identificó que los desafíos que enfrenta el Ministerio de Salud para la ejecución de la Política Nacional de Atención Integral a la Salud del Hombre pueden dividirse en dos clases: la primera relacionada con el hombre y la segunda relativa a los servicios de salud que se ofrecen actualmente a los hombres.

Al analizar a los varones, la razón principal expresada por los sujetos para la baja demanda de los servicios de salud se atribuye a la visión masculina de que el cuidado es una tarea femenina, y esta actitud, agregada a las demandas masculinas relacionadas con el trabajo que dificultan el acceso a los servicios de salud, debido a la pérdida de tiempo en las colas para las consultas médicas y la falta de orientación específica para la salud del hombre, problemas que se atribuyen a los servicios de salud, son los principales desafíos para la implementación de la Política Nacional de Atención Integral a la Salud del Hombre.

Llegamos a la conclusión de que el primer tema a ser discutido al principio para que esta política tenga éxito es la cuestión del reconocimiento de las necesidades de salud de los hombres, pero estas necesidades sólo pueden ser percibidas a través del análisis de la demanda de atención para estos usuarios, que debe ser un aspecto importante para la organización de la salud. Por lo tanto, examinar lo que los hombres buscan en un centro de salud, y a partir de este análisis planear acciones con el fin de satisfacer las demandas de salud de la población masculina, son medidas que se pueden tomar a través de la reestructuración de las Unidades Básicas de Salud y del trabajo de los profesionales que atienden a los varones.

\section{REFERENCIAS}

1. Aquino EML. Gênero e saúde: perfil e tendências da produção científica no Brasil. Ver Saúde Pública. 2006;40(n esp):121-32. 
2. Pinheiro TF, Couto MT, Silva GSN. Questões de sexualidade masculina na atenção primária à saúde: gênero e medicalização. Interface (Botucatu). 2011;15(38):845-58.

3. Courtenay WH. Constructions of masculinity and their influence on men's wellbeing: a theory of gender and health. Soc Sci Med. 2000;50:1385-1401.

4. Schraiber LB, Gomes R, Couto MT. Homens e saúde na pauta da saúde coletiva. Cienc Saúde Coletiva. 2005;10(1):7-17.

5. Couto MT, Pinheiro TF, Valença O, Machin R, Silva GSN, Gomes R et al. O homem na atenção primária à saúde: discutindo (in)visibilidade a partir da perspectiva de gênero. Interface (Botucatu). 2010;14(33):257-70.

6. Figueiredo W. Assistência à saúde dos homens: um desafio para os serviços de atenção primária. Ciênc Saúde Coletiva. 2005;10(1):105-9.

7. Villela W, Monteiro S, Vargas E. A incorporação de novos temas e saberes nos estudos em saúde coletiva: o caso do uso da categoria gênero. Cienc Saúde Coletiva. 2009;14(4):997-1006.

8. Keijzer B. Hasta donde el cuerpo aguante: género, cuerpo y salud masculina. In: Cáceres C, Cueto M, Ramos M, Vallens S (coord.). La salud como derecho ciudadano: perspectivas y propuestas desde América Latina. Facultad de Salud Pública y Administración de la Universidad Peruana Cayetano Herida, Lima. 2003.

9. Machado MF, Ribeiro MAT. Os discursos de homens jovens sobre o acesso aos serviços de saúde. Interface (Botucatu). 2012;16(41):343-56.

10. Melo EM, Cortes MCJW, Miranda PSC, Câmara ACS, Alves RA, Pereira VON et al. Eles morrem mais do que elas: Por que? Rev Méd Minas Gerais. 2008;18(4 supl. 4):S12-18.

11. Brasil. Ministério da Saúde. Secretaria de Atenção à Saúde. Departamento de Ações Programáticas Estratégicas. Política Nacional de Atenção Integral à Saúde do Homem (princípios e diretrizes). Brasília, 2008.

12. Gomes R, Nascimento E, Araujo FC. Por que os homens buscam menos os serviços de saúde do que as mulheres? As explicações de homens com baixa escolaridade e homens com ensino superior. Cad Saúde Pública. 2007;23(3):56574.

13. Nascimento FE, Gomes R. Marcas identidárias masculinas e a saúde dos homens jovens. Cad Saúde Pública. Julho, 2008.

14. Pinheiro RS, Viacava F, Travassos C, Brito AS. Gênero, morbidade, acesso e utilização de serviços de saúde no Brasil. Cienc Saúde Coletiva. 2002;7(4):687707.

15. Machin R, Couto MT, Silva GSN, Schraiber LB, Gomes R, Figueiredo WR et al. Concepções de gênero, masculinidade e cuidados em saúde:estudo com profissionais de saúde da atenção primária. Ciênc. saúde coletiva. $2011 ; 16(11): 4503-12$.

16. Laurenti R, Jorge MHPM, Gotlieb SLD. Perfil epidemiológico da morbi-mortalidade masculina. Ciênc Saúde Coletiva. 2005;10(1):35-46.

17. Figueiredo WS, Schraiber LB. Concepções de gênero de homens usuários e profissionais de saúde de serviços de atenção primária e os possíveis impactos na saúde da população masculina, São Paulo, Brasil. Ciênc Saúde Coletiva. 2011;16(supl. 1):935-44.

18. Gomes R, Schraiber LB, Couto MT, Valença OAA, Silva GSN, Figueiredo WS et al. $\mathrm{O}$ atendimento à saúde de homens: estudo qualitativo em quatro estados Brasileiros. Physis. 2011;21(1):113-28.

19. Santos FA. Dinâmica da acessibilidade masculina ao Programa Saúde da Família [dissertação]. Jequié: Universidade Estadual do Sudoeste da Bahia; 2010. 
20. Carrara S, Russo JA, Faro L. A política de atenção à saúde do homem: os paradoxos da medicalização do corpo masculino. Physis. 2009;19(3):659-78.

21. Mendes KDS, Silveira RCCP, Galvão CM. Revisão integrativa: método de pesquisa para a incorporação de evidências na saúde e na enfermagem. Texto Contexto Enferm. 2008;17(4):758-64.

22. Souza MT, Silva MD, Carvalho R. Revisão integrativa: o que é e como fazer. Einstein. 2010;8:102-6.

23. Nascimento ARA, Trindade ZA, Gianordoli-Nascimento IF, Pereira FB, Silva SATC, Carello AC. Masculinidades e práticas de saúde na região metropolitana de Belo Horizonte - MG. Saúde Soc. 2011;20(1):182-94.

24. Braz M. A construção da subjetividade masculina e seu impacto sobre a saúde do homem: reflexão bioética sobre justiça distributiva. Ciênc Saúde Coletiva. 2005;10(1):97-104.

25. Siqueira FA, Silva SO, Benevides PM, Almeida MSB, Lima TNB, Prest Bisneto F. Promoção e prevenção à saúde sexual masculina: desafios das equipes de Saúde da Família José Pinheiro 1. Rev Bras Ciênc Saúde. 2011;15(2):191-200.

26. Osorio RG, Servo LMS, Piola SF. Necessidade de saúde insatisfeita no Brasil: uma investigação sobre a não procura de atendimento. Ciênc Saúde Coletiva. 2011;16(9):3741-54.

27. Schraiber LB, Figueiredo WS, Gomes R, Couto MT, Pinheiro TF, Machin R et al. Necessidades de saúde e masculinidades: atenção primária no cuidado aos homens. Cad Saúde Pública. 2010;26(5):961-70.

28. Alves RF, Silva RP, Ernesto MV, Lima AGB, Souza FM. Gênero e saúde: o cuidar do homem em debate. Psicol Teor Prat. 2011;13(3):152-66.

29. Silva PAS, Furtado MS, Guilhon AB, Souza NVDO, David HMSL. A saúde do homem na visão dos enfermeiros de uma unidade básica de saúde. Esc Anna Nery. 2012;16(3):561-8.

30. Brito RS, Santos DLA, Maciel PSO. Olhar masculino acerca do atendimento na estratégia saúde da família. Rev RENE. 2010;11(4):135-42.

31. Stetler CB, Brunell M, Giuliano KK, Morsi D, Prince L, Newell-Stokes V. Evidencebased practice and the role of nursing leadershirp. JONA. 1998;28(7-8):45-53. 